\title{
eHealth technologies assisting in identifying potential adverse interactions with complementary and alternative medicine (CAM) or standalone CAM adverse events or side effects: a scoping review
}

\author{
Jeremy Y. $\mathrm{Ng}^{*}$ (D), Maryam Mooghali and Vanessa Munford
}

\begin{abstract}
Background: While there are several existing eHealth technologies for drug-drug interactions and stand-alone drug adverse effects, it appears that considerably less attention is focussed on that of complementary and alternative medicine (CAM). Despite poor knowledge of their potential interactions and side effects, many patients use CAM. This justifies the need to identify what eHealth technologies are assisting in identifying potential 1) adverse drug interactions with CAM, 2) adverse CAM-CAM interactions or 3) standalone CAM adverse events or side effects.

Methods: A scoping review was conducted to identify eHealth technologies assisting in identifying potential adverse interactions with CAM or standalone CAM adverse events or side effects, following Arksey and O'Malley's five-stage scoping review framework. MEDLINE, EMBASE, and AMED databases and the Canadian Agency for Drugs and Technologies in Health website were systematically searched. Eligible articles had to have assessed or referenced an eHealth technology assisting in identifying potential one or more of the three aforementioned items. We placed no eligibility restrictions on type of eHealth technology.

\footnotetext{
* Correspondence: ngjy2@mcmaster.ca; https://orcid.org/0000-0003-00315873;

Department of Health Research Methods, Evidence, and Impact, Faculty of Health Sciences, McMaster University, Michael G. DeGroote Centre for Learning and Discovery, Room 2112, 1280 Main Street West, Hamilton, Ontario L8S 4K1, Canada
}

C The Author(s). 2020 Open Access This article is licensed under a Creative Commons Attribution 4.0 International License, which permits use, sharing, adaptation, distribution and reproduction in any medium or format, as long as you give appropriate credit to the original author(s) and the source, provide a link to the Creative Commons licence, and indicate if changes were made. The images or other third party material in this article are included in the article's Creative Commons licence, unless indicated otherwise in a credit line to the material. If material is not included in the article's Creative Commons licence and your intended use is not permitted by statutory regulation or exceeds the permitted use, you will need to obtain permission directly from the copyright holder. To view a copy of this licence, visit http://creativecommons.org/licenses/by/4.0/ The Creative Commons Public Domain Dedication waiver (http://creativecommons.org/publicdomain/zero/1.0/) applies to the data made available in this article, unless otherwise stated in a credit line to the data. 
(Continued from previous page)

Results: Searches identified 3467 items, of which 2763 were unique, and 2674 titles and abstracts were eliminated, leaving 89 full-text articles to be considered. Of those, 48 were not eligible, leaving a total of 41 articles eligible for review. From these 41 articles, 69 unique eHealth technologies meeting our eligibility criteria were identified. Themes which emerged from our analysis included the following: the lack of recent reviews of CAM-related healthcare information; a large number of databases; and the presence of government adverse drug/event surveillance.

Conclusions: The present scoping review is the first, to our knowledge, to provide a descriptive map of the literature and eHealth technologies relating to our research question. We highlight that while an ample number of resources are available to healthcare providers, researchers, and patients, we caution that the quality and update frequency for many of these resources vary widely, and until formally assessed, remain unknown. We identify that a need exists to conduct an updated and systematically-searched review of CAM-related healthcare or research resources, as well as develop guidance documents associated with the development and evaluation of CAM-related eHealth technologies.

Keywords: Adverse events, Complementary and alternative medicine, eHealth, eHealth technologies, Herbdrug interactions, mHealth, Scoping review, Side effects

\section{Background}

Considerable research has established that the concurrent use of pharmaceutical drugs and complementary and alternative medicines (CAMs) can lead to unwanted interactions; furthermore, certain CAMs have been shown to cause standalone adverse reactions [1]. It is currently estimated that more than $70 \%$ of North Americans have tried at least one form of CAM, which includes traditional medicines [2-4], and collectively spend billions of dollars on these therapies each year $[5,6]$. An integral part of CAMs include natural health products (NHPs) in Canada, which are sold directly to Canadians and do not require a prescription nor the oversight of a healthcare professional, despite being regulated by Health Canada [7]. A 2010 Ipsos-Reid poll showed that 73\% of Canadians took NHPs regularly [8], yet only $19 \%$ of Canadians surveyed by Health Canada considered themselves well-informed when purchasing NHPs. Furthermore, $12 \%$ of Canadians who used NHPs report that they experienced adverse reactions, and only $41 \%$ of Canadians who experienced adverse effects from NHPs reported them [8].

eHealth is used widely in managing patients' medications, however, it is currently unknown what types of eHealth technologies are available to detect potential drug interactions with CAM or standalone CAM adverse effects. With regard to pharmaceutical technologies, there are some useful medication databases available that can be integrated into hospitals' electronic data and used as a tool for computerized decision support systems (CDSS). Studies on programs such as the Swedish Finnish Interaction X-referencing or SFINX database have demonstrated a correlation between medication alert systems and a decrease in potentially adverse drug interactions [9]. In some hospitals, medication-related CDSSs are used which evaluate drug dosage, patients' age, and comorbidities and send alarms when possible drug interactions and side effects are detected [10].

Additionally, there are several mobile apps that provide beneficial information regarding appropriate dosing, potential drug-drug interactions, and side effects. WebMD, Medscape, Epocrates, The Blue Book, and Micromedex are some of the most commonly used mobile drug information apps [11]. These types of mobile health (mHealth) apps are used by both health professionals and patients, and many are publicly available in the Google Play or the Apple App Store [12]. Some mobile apps have been developed to assist patients taking high-risk medications to manage their symptoms. For example, an app was developed by a team of collaborators in Oxford for patients undergoing treatment for colorectal cancer. This type of mHealth system shares the data recorded by the patient in symptom diaries with their health professional and will generate an alarm if a serious side effect occurs [13].

Moreover, computer-assisted history-taking systems (CAHTS) are other eHealth tools that have the potential to improve the monitoring of drug interactions and side-effects. CAHTS allow patients to enter their medication history prior to consultations, resulting in a more comprehensive record of medication information [14].

While there are several existing eHealth technologies for drug-drug interactions and stand-alone drug adverse effects, it appears that considerably less 
attention is focussed on CAM-drug interactions, CAM-CAM interactions, and standalone CAM adverse effects. Despite poor knowledge of their potential interactions and side effects, many patients use CAM. This justifies the need to identify what eHealth technologies exist for such CAM-related interactions and adverse effects.

\section{Methods}

\section{Approach}

A scoping review was conducted to identify eHealth technologies assisting in identifying potential adverse interactions with CAM or standalone CAM adverse events or side effects, following Arksey and O'Malley's [15] five-stage scoping review framework, and supplemented by Levac, Colquhoun, \& O'Brien [16] and Daudt, van Mossel, \& Scott [17] which build upon Arksey and O'Malley's work. The five steps are as follows: (1) identifying the research question, (2) identifying relevant studies, (3) selecting the studies, (4) charting the data, and (5) collating, summarizing, and reporting the results. This method was chosen in order to fulfill the prerequisites of a scoping review, which involve searching for and assessing the available literature on a given topic in order to identify the characteristics of eligible articles, summarize their contents and highlight knowledge gaps. We did not register a protocol.

\section{Step 1: identifying the research question}

The research question for this scoping review was as follows: "What eHealth technologies are assisting in identifying potential 1) adverse drug interactions with CAM, 2) adverse CAM-CAM interactions or 3) standalone CAM adverse events or side effects?". While a multitude of definitions for "eHealth" exists [18], for the purpose of this scoping review, in order to define parameters of eHealth, we considered 3 domains and their subcategories based on a study by Shaw et al. [19]. The framework for defining eHealth technologies are summarized in Table 2 in Appendix 3 of their paper. CAM has also been defined in a multitude of ways [20], however, the $\mathrm{Na}$ tional Center for Complementary and Integrative Health $(\mathrm{NCCIH})$ defines a non-mainstream practice used together with conventional medicine as "complementary", a non-mainstream practice used in place of conventional medicine as "alternative", and the coordinated delivery or use of conventional and complementary approaches as "integrative" [21]. For the purpose of this scoping review, in order to define parameters of eHealth, we considered Wieland et al.'s [22] bibliometric and content analysis of the Cochrane Complementary Medicine Field specialized register of controlled trials, where the authors collected the number of CAM field specialized register citations classified by type of CAM therapies. What was included as CAM are shown in Table 4 in Appendix 3 of their paper. Finally, we define the term "adverse event" as "any untoward medical occurrence that may present during treatment with a medicine but which does not necessarily have a causal relationship with this treatment", and "side effect" as "any unintended effect of a pharmaceutical product [or CAM] occurring at doses normally used in man, which is related to the pharmacological proprieties of the drug [or CAM]". Our definition of the terms "adverse event" and "side effect" correspond with that of the World Health Organization [23].

\section{Step 2: finding relevant studies}

Following a preliminary scan of the literature, an experienced academic librarian was consulted to assist in devising a comprehensive, systematic search strategy on MEDLINE, EMBASE, and AMED academic databases. The search included literature published from 1995 up until November 6, 2019, as eHealth was only popularized in the late 1990 s with the term itself was coined in 1999 [24]. The search strategy included Medical Subject Headings and keywords that reflect terms commonly used in the literature to refer to both eHealth and CAM. Following preliminary searches, it was decided not to also include search terms relating to adverse events or side effects, as many eligible articles were found to not be indexed using them and thus this would have excluded them. Additionally, the Canadian Agency for Drugs and Technologies in Health (CADTH) website (https://www.cadth.ca/) was also searched to account for any grey literature; terms searched included "eHealth", "mHealth", "complementary and alternative medicine" and "herbal". A search strategy we used including Medical Subject Headings and keywords that reflect terms commonly used in the literature to refer to CAM and eHealth can be found in Appendix 1.

\section{Step 3: selecting the studies}

Preliminary searches indicated that the academic literature on this subject area exists as eligible articles could be found. We included primary research articles and research protocols; any relevant reviews were used to source additional eligible primary research articles or research protocols. In order to be included, the article had to have included an eHealth technology (either the authors' own or referenced) of any kind that was assisting in identifying potential 1) adverse drug interactions with CAM, 2) adverse 
CAM-CAM interactions, or 3) standalone CAM adverse events or side effects, otherwise they were excluded. At this stage, articles were excluded if they did not make reference to our research question. Publications in the form of conference abstracts were not eligible. We also restricted eligibility to articles published in the English language and that were either publicly available or could be ordered through our library system. If there was any uncertainty, the article's full-text was reviewed to determine eligibility. We placed no eligibility restrictions on type of eHealth technology; even if they were only accessible in a non-English language, we included them as long as English literature was written about them. All three authors (JYN, MM, and VM) pilot-screened a subset of all titles and abstracts independently and met to verify their agreement in applying the inclusion criteria prior to screening all items, including the full-texts of potentially eligible articles, independently in triplicate. Disagreement was solved by discussion, and in the case that consensus could not be reached, a majority vote was used to determine eligibility.

\section{Step 4: charting the data}

Articles meeting the inclusion criteria were critically reviewed using Arksey and O'Malley's [15] descriptive-analytical narrative method. For each eligible article, the following data were extracted and charted: article title; author(s); year of publication; study country; study design; whether the article was original research or a review of resources; study aim; and name of eHealth technology(s) assessed or referenced in the eligible article that we assessed in this scoping review. For each included eHealth technology, the following data were extracted and charted: name; URL (if available), type (i.e. adverse drug reporting system, database, factsheets, etc.), format (i.e. website, mobile app, etc.), year established; if the eHealth technology still exists; whether it has been used in any context outside of the authors' study; whether it is free and/or available to anyone; developer (and category); purpose; and intended user(s). All three authors (JYN, MM, and VM) participated in a pilot data extraction of a subset of eligible articles/eHealth technologies, and MM and VM independently extracted data from all eligible articles as well as from all eHealth technologies (i.e. the authors' own or referenced). All three authors then met to discuss and resolve discrepancies. We did not conduct a critical appraisal of included sources of evidence nor did we collect included articles' sources of funding, as no prior scoping review had been conducted on this topic before, thus we only aimed to provide a descriptive map of the literature and highlight a number of key themes that emerged from our analysis.

\section{Step 5: collating, summarizing, and reporting the results}

Charted data was summarized in the format of tables, and the descriptive data were analysed using content analysis. All three authors (JYN, MM, and VM) reviewed the descriptive data, and JYN identified codes relative to the findings, organized codes into thematic groups, and presented a narrative relating to the research question as well as highlighted knowledge gaps in the currently existing literature. All three authors then met to discuss and resolve discrepancies.

\section{Results}

\section{Search results}

Searches identified a total of 3467 items, of which 2763 were unique, and 2674 titles and abstracts were eliminated, leaving 89 full-text articles to be considered. Of those, 48 were not eligible, because they did not include eHealth technology meeting eligibility criteria $(n=44)$ or were an abstract $(n=4)$, leaving a total of 41 articles that were included in this scoping review [25-65]. A PRISMA diagram can be found in Fig. 1 of Appendix 2.

\section{Eligible article characteristics}

Eligible articles were published from 1997 to 2019 and originated from the United States $(\mathrm{n}=16)$, China $(\mathrm{n}=8)$, Germany $(\mathrm{n}=3)$, Republic of Korea $(\mathrm{n}=3)$, Singapore $(\mathrm{n}=3)$, Canada $(\mathrm{n}=1)$, Denmark $(\mathrm{n}=1)$, Greece $(n=1)$, Italy $(n=1)$, Sweden $(n=1)$, and United Kingdom $(n=1)$. Additionally, one study involved researchers from Australia, China, and Germany $(n=1)$, and another from China and the United Kingdom ( $\mathrm{n}=$ 1 ). Of the 41 articles included, 27 were primary research articles with the following study designs: development $(n=12)$ or evaluation $(n=7)$ of an eHealth technology, analysis of data collected by an eHealth technology $(n=7)$, and a usability study $(n=1)$; the remaining 14 articles were reviews of one or more medical information resource(s) including at least one containing an eHealth technology addressing our research question. Here, we define a "review" as an article that reviewed an aspect of the entirety of an eligible eHealth technology, and not necessarily a systematic or scoping review. The details associated with all eligible article characteristics, including study aims, can be found in Table 1 of Appendix 3. 


\section{eHealth technology characteristics}

Of the 69 included eHealth technologies, we characterized them as follows: databases $(n=34)$, factsheets/healthcare information $(n=13)$, adverse drug/ event alerting, reporting and/or signal detection systems $(n=11)$, search engines $(n=4)$, interaction checkers (standalone) $(\mathrm{n}=1)$, bulletin $(\mathrm{n}=1)$, continuing education module $(n=1)$, electronic pharmacovigilance system $(\mathrm{n}=1)$, model $(\mathrm{n}=1)$, and serious game $(n=1)$. Additionally, one eHealth technology is both an adverse drug reaction detection/spontaneous reporting system and a database. These eHealth technologies were offered in the following formats: websites/web-based only $(\mathrm{n}=38)$, website and mobile app $(n=10)$, mobile app only $(n=6)$, software $(n=2)$, artificial intelligence $(n=1)$. The format was unclear for the remaining twelve. In many cases, it was difficult to ascertain the year the eHealth technology was created $(n=29)$, however, 15 were identified to have been created from at least the mid-1970s to 2000, another 15 from 2001 to 2010, and 10 from 2011 to 2019. Forty-eight eHealth technologies were identified to currently exist, while 2 did not, and 1 was replaced by one of the 48 , and for the remaining 18 , their current existence was unclear. We found that 60 eHealth technologies had been used in any context outside of the authors' study; for example, the technology or its data were cited in another research article not conducted by the developing authors. Thirty-two eHealth technologies were found to be available and entirely free to use by anyone, 12 are only accessible with a subscription, 1 was partially available without a subscription, required a partialsubscription, 3 were confirmed to be not available to the general public, and the status of the remaining 21 was unclear. eHealth technologies were developed by the following: companies $(n=24)$, researchers or research groups $(n=22)$ (11 of which by the authors of one or more of the eligible articles), government agencies/departments $(n=17)$, botanical council $(n=1)$, not-for-profit $(n=1)$, practitioners $(n=1)$, unclear $(n=1)$. Additionally, 2 were developed by organizations that involved both researchers and government. Intended users of the eHealth technologies were not always clear, and we used our discretion in cases where this information was not provided explicitly. Our assessment was as follows: for healthcare providers $(n=54)$, for researchers $(n=36)$, for patients/ public $(n=32)$. These numbers reflect a large amount of overlap among these user types across many of the eHealth technologies. The details associated with all included eHealth technologies can be found in Table 2 of Appendix 3.

\section{Findings from thematic analysis}

In total, three main themes emerged from our analysis and are described below.

\section{Obsolete reviews of CAM-related healthcare information} Upon accounting for all eligible articles, one immediate and striking finding was the fact that while a number of reviews have been published providing overviews or summaries of CAM-related healthcare or research resources, they have all been published in excess of one decade ago, with the exception of Xie et al. [41]'s review, however it is only specific to natural product databases. The most recent reviews providing information on CAM, in general, were published approximately $15-20$ years ago [25, $28,32,33,48,50,56,65]$. As a result, the information contained within these articles is all, to varying extents, obsolete, including resources that are no longer available or updated. Furthermore, as these articles were published years before the methodologies of systematic or scoping reviews were published, many resources included in these reviews were found unsystematically or based on the authors' knowledge.

\section{Large number of databases}

It was found that a large number of databases exist, primarily offered in website and/or mobile app formats, making up the largest category of types of eHealth technology in this scoping review (35 of 69). New databases have been created (and maintained) since the 1970s up to the present day, and their developers and content vary fairly widely. Perhaps unsurprisingly, the vast majority of databases developed by companies focus on the provision of resources for healthcare providers. These include a number of well-recognized, large companies in the healthcare industry, providing items such as monographs, clinical decision suites, dosing calculators and adverse event/interaction checkers in their respective databases [66-71]. In contrast, databases developed by government organizations or agencies collect information at the population level regarding pharmacovigilance and adverse events $[49,72,73]$, though databases such as the Drug Product Database available on the Health Canada website also provides a search tool for drugs and certain natural health products available nationally with associated monographs. Interestingly, most databases developed by researchers or research groups emerge from Asia (notably China and the Republic of Korea). These databases serve a different purpose than the aforementioned company- and government-developed ones, instead housing information on traditional 
medicine (i.e. traditional Chinese medicine) ingredients such as interactions, mechanisms of action, compound structures, and their relationship to genes and diseases [30, 31, 39-41, 47, 55].

We did not formally assess the usability of these databases or the quality of the information contained within them, as this exceeded the scope of this scoping review. Despite this, it should be noted that initial impressions obtained simply by completing the data extraction step for this review indicated that these databases likely vary largely in quality, and the authors intend on assessing this in a future research study. The frequency of updates for each database is presented in Table 3 in Appendix 3; some of the most recent databases (updated and/or created within the last 3 years) are presented in Table 4 in Appendix 3.

\section{Government adverse drug/event surveillance}

We identified that the majority of adverse drug/ event surveillance eHealth technologies including CAM identified were government initiated, and found across the following countries: China, India, the Republic of Korea, and the United States. These eHealth technologies are equipped with detection [34] and reporting systems [27, 31, 34, 74] and safety alerts $[74,75]$. The countries with such government initiatives outside of the United States are unsurprising, given that a very large proportion of traditional and indigenous medical systems originate from these parts of the world, notably traditional Chinese and Korean medicine and Ayurvedic medicine [76]. Though a not-for-profit, as opposed to a government agency, our review also captured the Institute for Safe Medication Practices in Canada which runs a medication error reporting program and publishes newsletters, reports and safety alerts based on information received [77]. These government initiatives highlight the growing need to collect information surrounding CAM-related adverse events and side effects given they are widely used across the globe [78].

\section{Discussion}

The purpose of the present scoping review was to identify eHealth technologies that assist in identifying potential 1) adverse drug interactions with CAM, 2) adverse CAM-CAM interactions, or 3) standalone CAM adverse events or side effects. The amount of available literature on this topic as well as the number of eHealth technologies, while not overly voluminous, presents a broad range of different eHealth technologies that have emerged since the popularization of (and even before) the term "eHealth". Given that, to our knowledge, this is the first study to present such eHealth technologies using a systematic search of the peer-reviewed and grey literature, it is hoped that these findings will provide both healthcare providers and researchers with an awareness of what research has taken place over the past few decades at the intersection of CAM and eHealth.

\section{Resources for practitioners, researchers and patients: ample, but of unclear quality}

This review also provides readers with a list of currently existing resources that they may not have been aware of to date, which may aid in their clinical practice or research. While these resources have been developed, evaluated, studied or assessed, at least to some degree, by academic researchers, this review was only designed to scope out the number of eHealth technologies and their key characteristics. Unfortunately, we did not find that any authors of included articles expressed an intention to create new upcoming eHealth technologies in this topic area, beyond improving their own existing resource. As expected, our scoping review captured some well-known and authoritative resources, such as Natural Medicines [69], MicroMedex [67] and the NCCIH's Herbs at a Glance [79], however, some others may be less known and their quality may be questionable. Therefore, we encourage users of any of these resources to exercise caution and use their professional judgement when utilizing any of these resources, especially those which may be unfamiliar to them.

\section{Areas identified for future research}

We have identified a couple of areas for future research based on our findings.

Today there exists more information on the Internet about CAM and CAM-related adverse events and side effects than ever before, yet the quality of much of it is arguably questionable [80]. Clinicians, researchers, governments and policymakers, and patients alike all need resources that provide them with reliable, trustworthy, and current information. Combined with our finding that the vast majority of reviews on CAM-related healthcare or research resources are now decades old, this undoubtedly justifies a need for an updated review of CAM-related healthcare information given that many changes have occurred in the way in which both guidelines inform clinical practice and research methodologies have evolved.

While we did not formally assess the quality of the eHealth technologies (nor the information they contained), it was evident at face-value that they 
varied across eHealth technologies across all types, developers and content areas. We hypothesize that this may relate to the fact that little guidance exists in developing or evaluating CAM-related eHealth technologies, as the growth of research conducted in this area has been slow and the information limited. While there have been discussions surrounding the creation of comprehensive information resources about CAM, it appears that the most recent ones took place nearly two decades ago $[81,82]$, based on preliminary searches we conducted prior to finalizing our systematic search strategy. The development of CAM-related eHealth technologies should be viewed as a research method in itself similar to how guidelines for different study types exist [83]. As a result, additional and updated guidance documents are needed in creating eHealth technologies, let alone CAM-related ones, as to date only one appears to exist [84].

\section{Strengths and limitations}

Notable strengths of this study included the use of a comprehensive systematic search strategy to identify eligible articles, devised with the assistance of an experienced academic librarian. Interpretation of these findings was strengthened by the fact that all three authors independently screened, data extracted, and summarized the findings.

Limitations include the fact that this scoping review did not include non-English language articles, which perhaps would have been of importance given our finding that there is an emergence of new CAM-related eHealth technologies in Asia, among other countries. Additionally, it should be noted that many apps exist that likely also detect CAMrelated adverse events or side effects which were not captured by this search. Though this is a limitation, it can be inferenced that higher-quality apps (or at least those that have been exposed to peerreview) would be those that would be captured in the published literature, which would be of greater use to healthcare providers and researchers as the primary audience of this review. Furthermore, a very large number of poor-quality apps exist on platforms such as the Google Play Store and the Apple App Store, and it would not be practical nor feasible to review them all.

\section{Conclusion}

The present scoping review involved a systematic search of the literature to identify eHealth technologies assisting in identifying potential 1) adverse drug interactions with CAM, 2) adverse CAM-CAM interactions, or 3) standalone CAM adverse events or side effects. Having identified 69 unique eHealth technologies that fall into this category, we provide a descriptive map of the literature on this area and highlight a number of key themes that emerged from our analysis. Additionally, we highlight that while an ample number of resources are available to healthcare providers, researchers, and patients, we caution that the quality and update frequency for many of these resources vary widely, and until formally assessed, remain unknown. Lastly, we identify that a need exists to conduct an updated and systematically-searched review of CAM-related healthcare or research resources, as well as develop guidance documents associated with the development and evaluation of CAM-related eHealth technologies.

\section{Appendix 1 \\ Sample Search Strategy \\ MEDLINE Search Strategy for Scoping Review of eHealth Technologies Assisting in Identifying Poten- tial 1) Adverse Drug Interactions with CAM, 1) Ad- verse CAM-CAM Interactions or 3) Standalone CAM Adverse Events or Side Effects Executed November 6, 2019}

Database: Ovid MEDLINE(R) and Epub Ahead of Print, In-Process \& Other Non-Indexed Citations, Daily and Versions(R) $<1946$ to November 05, 2019>Search Strategy:

1 ((Alternative or Traditional or Complementary or Integrat*) adj2 (Therap* or Medicine*)).mp. [mp=title, abstract, original title, name of substance word, subject heading word, floating sub-heading word, keyword heading word, organism supplementary concept word, protocol supplementary concept word, rare disease supplementary concept word, unique identifier, synonyms] (103649)2 Complementary Therapies/ or Integrative Medicine/ or exp Medicine, East Asian Traditional/ or exp Medicine, Chinese Traditional/ or exp Herbal Medicine/ or exp Plants, Medicinal/ or exp Phytotherapy/ or exp Drugs, Chinese Herbal/ or exp Medicine, Ayurvedic/ (151984)3 (CAM or TCM or Traditional Chinese Medicine or Ayurved ${ }^{*}$ or Medicinal Plant* or Herbalism).mp. (69971)4 (Herb* adj1 (Medic* or Therap* or Supplement*)).mp. (23276)5 or/1-4 (248865)6 (Telemedicine or Telehealth or eHealth or e-Health or mHealth or m-Health or Mobile Health or Health Records, Personal or Mobile Application* or E-Prescription* or Electronic Prescri* or Electronic Health Record* or Electronic Medical Record* or Medical Records System* or Health Informatics or Medical Informatics or Computeri?ed Decision Support or Data Mining or Decision Support System* or Wearable Electronic Device* or Wearable Technolog* or Smartphone or Iphone or I-phone or Android or Handheld Computer or Personal* Digital or Deep Learning or Artificial Intelligence).mp. (166979)7 Telemedicine/ or Health Records, Personal/ or Mobile Applications/ or Electronic Prescribing/ or Medical Records Systems, Computerized/ or Medical Informatics/ or Drug Therapy, Computer-Assisted/ or Drug Information Services/ or Hospital Information System/ or Computing Methodologies/ or Wearable Electronic Devices/ or Artificial Intelligence/ or "Neural Networks (Computer)"/ (112744)8 or/6-7 (199016)9 5 and 8 (1157)10 limit 9 to (english language and $y r=" 1995$-Current") $(815)^{* * * * * * * * * * * * * * * * * * * * * * * *}$ 


\section{Appendix 2}

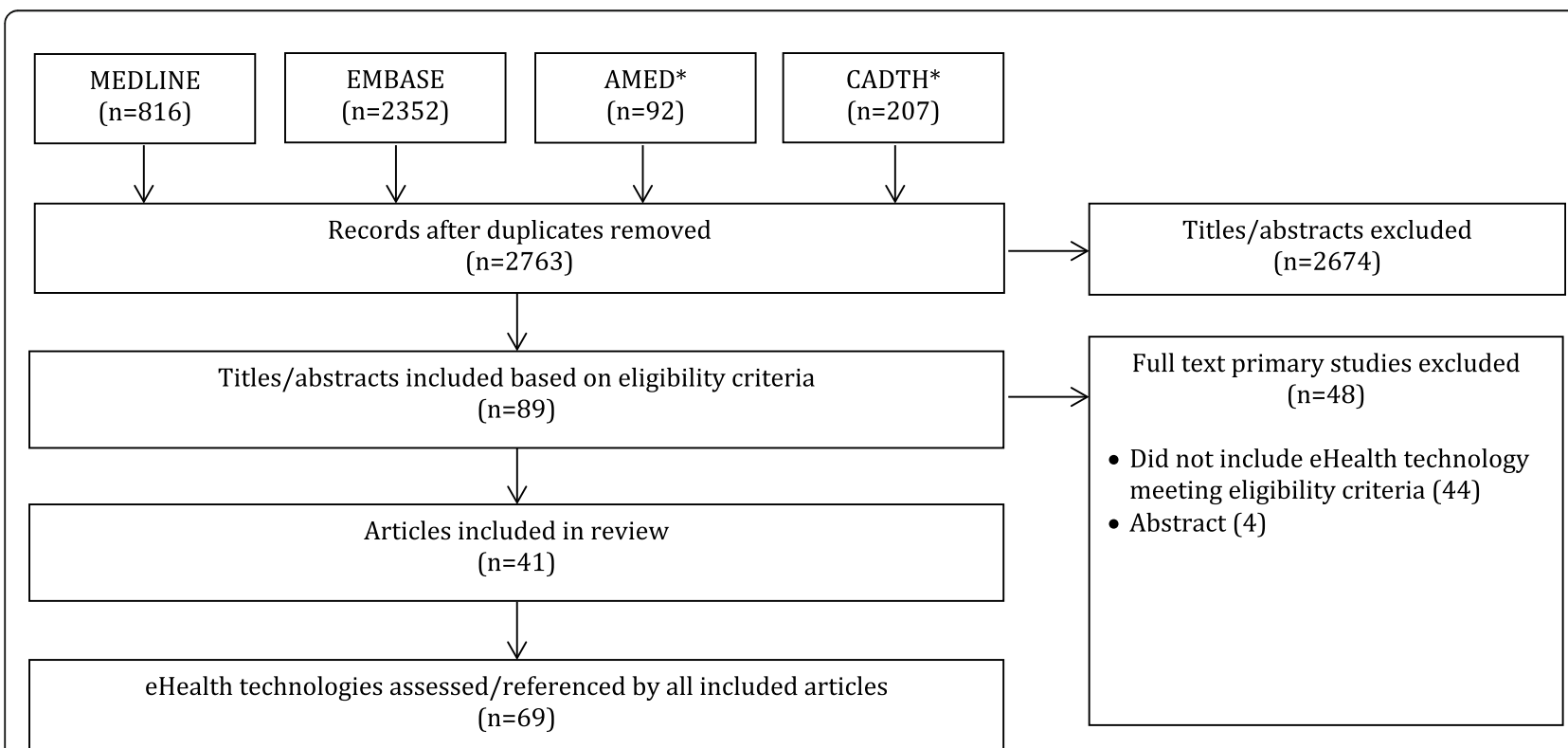

*List of Abbreviations: AMED = Allied and Complementary Medicine Database, CADTH = Canadian Agency for Drugs and Technologies in Health

Fig. 1 PRISMA Diagram. *List of Abbreviations: AMED = Allied and Complementary Medicine Database, CADTH=Canadian Agency for Drugs and Technologies in Health 


\section{Appendix 3}

\section{Data Extraction Tables}

Table 1 Eligible article characteristics $(n=41)$

\begin{tabular}{|c|c|c|c|}
\hline $\begin{array}{l}\text { First Author } \\
\text { and Year }\end{array}$ & Article title & $\begin{array}{l}\text { Study } \\
\text { Country }\end{array}$ & Study Design \\
\hline \multicolumn{4}{|c|}{ ORIGINAL RESEARCH ARTICLES $(n=27)$} \\
\hline $\begin{array}{l}\text { Archer } \\
\text { et al. } 2014 \\
\text { [35] }\end{array}$ & $\begin{array}{l}\text { Development of an alert system to detect } \\
\text { drug interactions with herbal supplements } \\
\text { using medical record data }\end{array}$ & USA & $\begin{array}{l}\text { Development of alert } \\
\text { system prototype }\end{array}$ \\
\hline $\begin{array}{l}\text { Boehmer } \\
\text { et al. } 2011 \\
\text { [53] }\end{array}$ & $\begin{array}{l}\text { Evaluating the value of a web-based natural } \\
\text { medicine clinical decision tool at an academic } \\
\text { medical center }\end{array}$ & USA & $\begin{array}{l}\text { Evaluation of web-basec } \\
\text { clinical decision tool }\end{array}$ \\
\hline $\begin{array}{l}\text { Brink et al. } \\
2004 \text { [60] }\end{array}$ & $\begin{array}{l}\text { Cancer CAM(TM): Web-based continuing edu- } \\
\text { cation for health professionals }\end{array}$ & USA & $\begin{array}{l}\text { Evaluation of online } \\
\text { continuing education } \\
\text { prototype module }\end{array}$ \\
\hline
\end{tabular}

Chen et al. Computer automated prediction of potential 2002 [29] therapeutic and toxicity protein targets of bioactive compounds from Chinese medicinal plants

Chen et al. Database of traditional Chinese medicine and China

2006 [30] its application to studies of mechanism and to prescription validation

\section{Ee et al. \\ 2018 [64] \\ Faubert \\ et al. 2010 \\ [54] \\ Fischer \\ et al. 2005 \\ [44] \\ Fucik et al \\ 2002 [49] \\ Herbopolis - A mobile serious game to educate players on herbal medicines \\ A pilot study to compare natural health product-drug interactions in two databases in Canada \\ Complementary and alternative medical reference software for personal digital assistants: evidence of clinical applicability \\ Building a computerized herbal substance register for implementation and use in the World Health Organisation International Drug Monitoring Programme}

Gao et al.

2015 [59]

et al. 2016

[42]

Hamre

et al. 2017

[61]

Kim et al.

2019 [45]

Lee et al.

2015 [40]

Li et al.

2009 [26] identified through an analysis of the Chinese Adverse Drug Reaction Information Bulletin 2001 to 2014

Characterization of complementary and alternative medicine-related consultations in an academic drug information service

Use and safety of anthroposophic medicinal products: An analysis of 44,662 patients from the EvaMed Pharmacovigilance Network

Drug repositioning of herbal compounds via a Republic machine-learning approach

PharmDB-K: Integrated bio-pharmacological network database for traditional Korean medicine

Republic of Korea database

Development of signal

detection system

Analysis of Adverse Drug Reaction Information Bulletin (ADRIB) reports

Analysis of complementary and alternative medicine drug information consultations

Analysis of EvaMed Pharmacovigilance Network diagnoses and prescriptions data

Development of algorithm

A web-based quantitative signal detection sys- China tem on adverse drug reaction in China
Pharmacovigilance in China: Issues of concern

Development of intelligence systems

Article Study aim

type

Original To develop an automated herb-drug inter-

Research action alert system prototype designed to alert physicians and patients of potential herb-drug interactions

Original To evaluate the impact that a natural medicine Research clinical decision tool has on faculty attitudes, practice experiences, and needs with respect to herbal and natural products

Original To describe "a formative evaluation of a web-

Research based continuing education program for nurses and patient health educators on CAM for cancer patients" (p. 44)

Original To determine the therapeutic and toxicity Research protein targets of Chinese medicinal plant compounds database and artificial

Original To collect quantitative information about Research traditional Chinese medicine (TCM) prescriptions, constituent herbs and herbal ingredients to create/test a database to assist with the studying and exploring of TCM

Original To develop a mobile game to motivate users Research to learn more about herbal medicine

Original To evaluate and compare two natural health Research product databases for the purpose of integrating them into a pharmacy information system in Canada

Original To evaluate the value and clinical applicability

Research of new complementary and alternative medicine software products

Original To build a computerized herbal substance Research register for implementation and use in the World Health Organisation International Drug Monitoring Programme
Original To analyse the reports in the ADRIB since its

Research first publication in 2001 to give international readers a better appreciation of the pharmacovigilance issues addressed

Original "To evaluate and characterize consultation Research requests received through our academic drug information consultation service related to complementary and alternative medicines" ( $p$. 540)

Original To determine the frequency of adverse drug

Research reactions to anthroposophic medicinal products (AMPs), relative to the number of AMP prescriptions.

Original "To predict new indications for existing drugs Research and additional herbal compounds based on a machine-learning approach" (p. 34)

Original To construct PharmDB-K, which offers compreResearch hensive information relating to Traditional Korean Medicine-associated drugs (compound), disease indication, and protein relationships

Original "To establish a web-based quantitative signal

Research detection system for adverse drug reactions based on spontaneous reporting to the 
Table 1 Eligible article characteristics ( $n=41)$ (Continued)

First Author Article title Study

and Year

Ogultarhan KATIS: An eHealth system for complementary et al. 2016 medicine

[36]

Olesen

et al. 2013

Absence of 'over-the-counter' medicinal

[43]

products in on-line prescription records: A risk

factor of overlooking interactions in the

elderly

Spanakis PharmActa: Empowering patients to avoid

et al. 2019 clinical significant drug-herb interactions

[46]

Sun et al

2019 [55]

Development of quantitative structure-activity relationship models to predict potential nephrotoxic ingredients in traditional Chinese medicines

Tabali et al. Adverse drug reactions for CAM and

2012 [62] conventional drugs detected in a network of physicians certified to prescribe CAM drugs

Walker

Evaluation of the ability of seven herbal

2002 [51]

resources to answer questions about herbal products asked in drug information centers

Woo et al. Safety of herbal medicine for elderly patients 2019 [31] with chronic disease in the Republic of Korea

ETCM: An encyclopaedia of traditional Chinese medicine

An ontology-based artificial intelligence model for medicine side-effect prediction: taking traditional Chinese medicine as an example

Utilizing mobile networks for the detection of clinically relevant interactions between chemotherapy regimens and complementary and alternative medicines China

Zhang
Country

Study Design

$(2$

Germany

Development of database and mobile app

Denmark Analysis of online prescription record data

Greece

Evaluation of mobile app

Development and testing of model

Analysis of adverse drug reactions in database

USA

Evaluation of databases

Republic of Korea

Analysis of spontaneous adverse event reports

Development of webbased encyclopedia

Development of artificial intelligence
China, Germany
Singapore

Development of an iPhone app

Development of signal detection system and reporting system

Analysis of pharmacovigilance of herbal and traditional medicines

\section{Article Study aim}

type

Guangdong province drug monitoring database in China" (p. 729)

Original To aggregate knowledge on complementary

Research and alternative medicine (CAM) into one database to allow for the search of CAM therapies, indications and interactions

Original "To assess possible origins of harmful Research interactions in elderly patients arising from the current absence of information on over-the counter (OTC) medicines in the Danish 'on-line prescription record"' (p. 145)

Original To discuss the use of personal health services Research and mobile health applications for patients and healthcare providers to avoid and manage drug-herb interactions, and to discuss a recently developed personalized pharmaceutical mobile health application called PharmActa

Original To develop a quantitative structure-activity reResearch lationship models to predict potential nephrotoxic ingredients in traditional Chinese medicines

Original "To describe and quantify the volume and Research severity of adverse drug reactions for complementary and alternative medicine (CAM) and conventional drugs in a proprietary database created from prescriptions and patient data of primary care CAM physicians who participate in the EvaMed Network" ( $p$. 427)

Original "To evaluate the ability of seven widely known Research herbal references and electronic databases to answer questions about herbal products asked at drug information centers" (p. 1611)

Original To investigate the detection of drug safety Research signals associated with herbal medicine by analyzing spontaneous adverse event reports in elderly patients with chronic diseases to generate new safety information

Original To develop an online encyclopedia to provide Research users information on traditional Chinese medicine herbs and formulas

Original To develop an ontology-based model for artifiResearch cial intelligence-assisted medicine side-effect prediction, and validate a proposed model consisting of three main components, including the drug model, the treatment model, and the artificial intelligence-assisted prediction model

Original "To develop a novel database application for Research the Mobile Internet called OncoRx-MI, the purpose of which is to detect drugcomplementary and alternative medicine interactions of both single-agent and multipleagent chemotherapy regimen prescriptions" (p. 166)

Original To develop a computerized signal detection Research system to detect adverse drug reactions

Original To differentiate the concepts of traditional/

Research complementary medicine and their products, and introduce the supervision and management systems of the China Food and Drug Administration and the differences between conventional medicine and 
Table 1 Eligible article characteristics $(n=41)$ (Continued)

\begin{tabular}{lll}
\hline $\begin{array}{l}\text { First Author Article title } \\
\text { and Year }\end{array}$ & $\begin{array}{l}\text { Study } \\
\text { Country }\end{array}$ & Study Design \\
\hline
\end{tabular}

REVIEWS $(n=14)$

Allais et al. Access to databases in complementary 2000 [65] medicine

Boddy et al. Review of reliable information sources related 2008 [52] to integrative oncology

Clauson Clinical decision support tools: Personal digital USA et al. 2008 assistant versus online dietary supplement

[37] databases

Fitzpatrick Natural standard database

2010 [38]

Jackson

An overview of information resources for

herbal medicinals and dietary supplements

Jackson

Resources for information on herbal

et al. 2001

medicinals and dietary supplements

[25]

Kiefer et al. Finding information on herbal therapy: a

2001 [32] guide to useful sources for clinicians

Meyer et al. Evaluation of herbal-drug interaction data in

2004 [33] tertiary resources

Molassiotis Quality and safety issues of web-based infor\& Zu 2004 mation about herbal medicines in the treat[58] ment of cancer

Motl et al. Health information websites by therapeutic 2004 [28] category for healthcare professionals

Sweet et al. Usefulness of herbal and dietary supplement 2003 [56] references

Natural Standard--New integrative medicine database

Wootton Directory of databases for research into

1997 [48] alternative and complementary medicine: An update

Xie et al.

Review of natural product databases
Italy

UK

USA

USA

Review of medical information resource(s)

USA

A

Review of medical
information resource(s)

USA

Review of medical information resource(s)

China, UK Review of medical information resource(s)

Review of medical information resource(s)

USA

Review of medical information resource(s)

USA

USA

Review of medical information resource(s)

Review of medical information resource(s)

China

Review of medical type

Study aim

traditional/complementary medicine products, taking drugs used in traditional Chinese medicine as an example

Review To review and categorize biomedical databases for complementary and alternative medicine

Review "To provide an overview of reliable integrative oncology information from various resources." (p. 620)

Review To "assess and compare the content of PDA dietary supplement databases and their online counterparts used as clinical support decision tools" p. 1593

Review To "provide an overview of Natural Standard and its content and scope, as well as provide some basics for searching this resource"( $p$. 154)

Review To "provide a comprehensive, annotated listing of reliable resources of information on herbs and dietary supplements divided into the following categories: journals, databases and websites, and books and compendia" ( $p$. 36)

Review To assess information on herbal medicinals and dietary supplements on AltMedDex

Review To provide primary care clinicians with a list of general, clinically oriented, evidence-based, English language references for Western herbal therapeutics that may be of practical use in the clinical setting

Review To objectively evaluate various tertiary resources using a set of predetermined criteria to assess which provide the most complete, current, and accurate herbal-drug interaction information

Review To assess the quality and safety of the information presented on the internet about medicinal herbs specifically in the field of cancer

Review "To compile and evaluate health information websites to aid healthcare professionals in locating information on select therapeutic categories" (p. 106)

Review "To describe the usefulness of some of the most common tertiary references that healthcare professionals employ to answer requests about herbal and dietary supplements" (p. 494)

Review To provide an overview of the Natural Medicines (Natural Standards) database

Review To provide a directory of databases for research into complementary and alternative medicine information resource(s)
Review To provide an overview and analysis of current natural product databases and discuss trends of future database development 


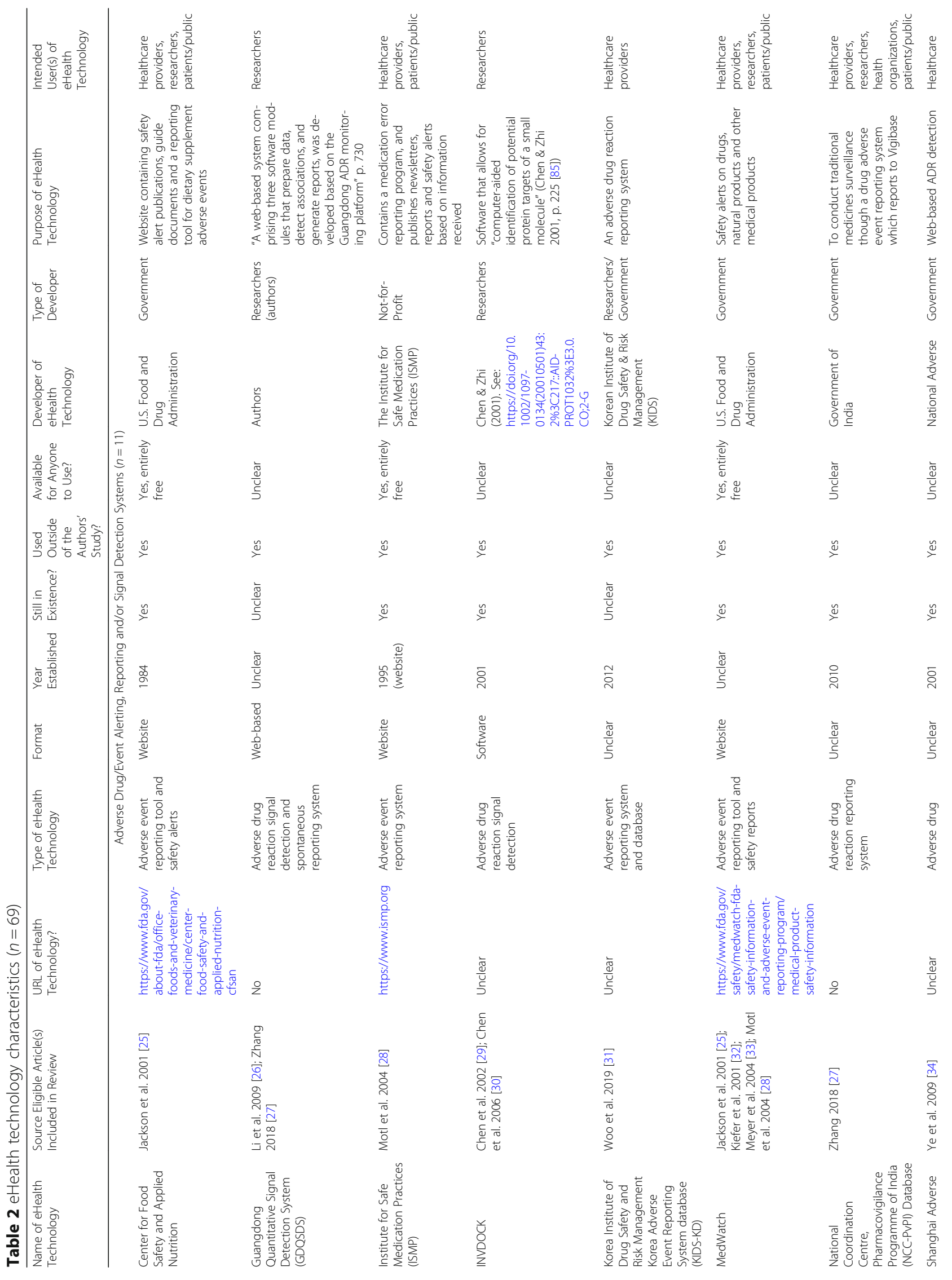




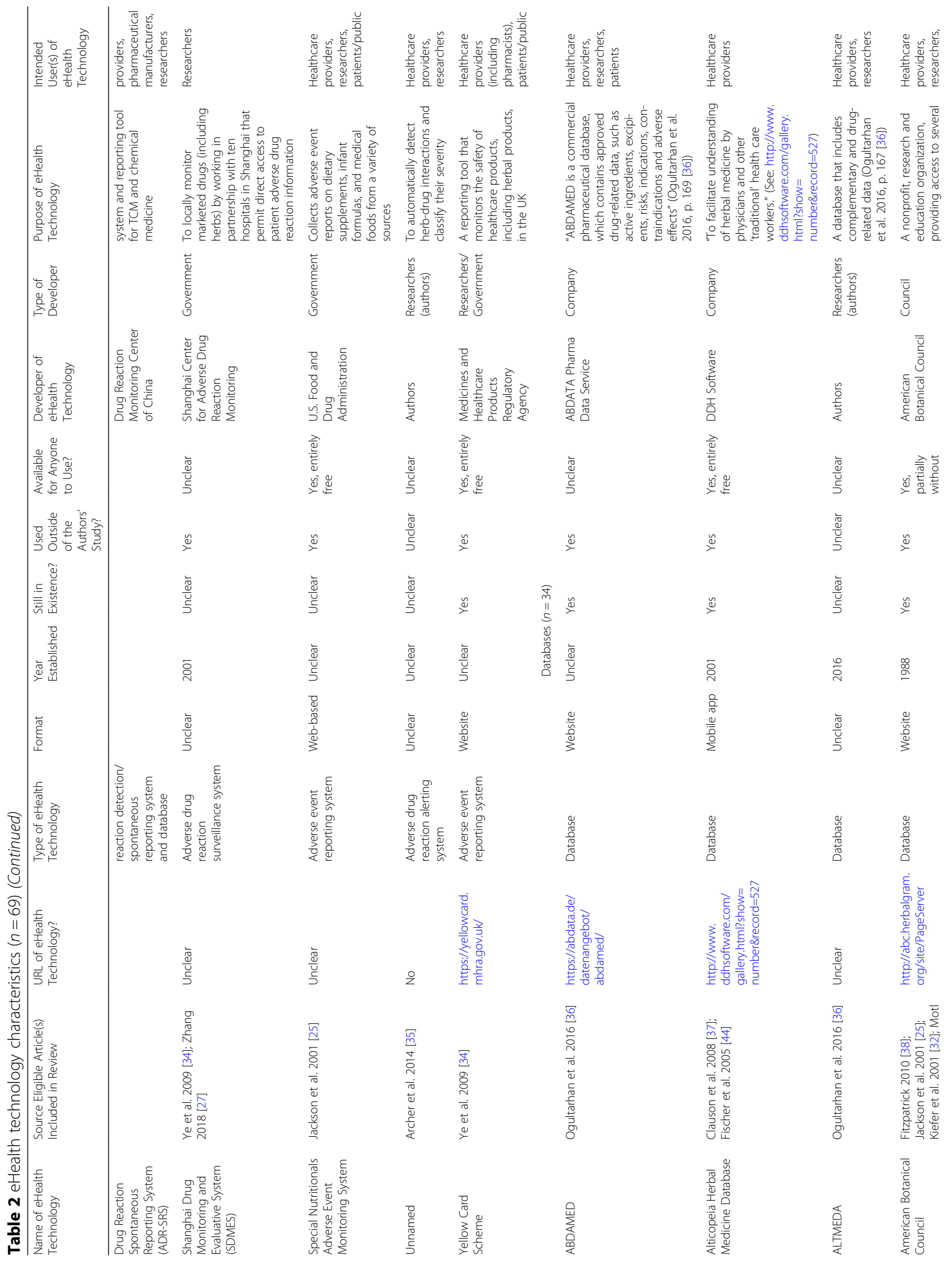




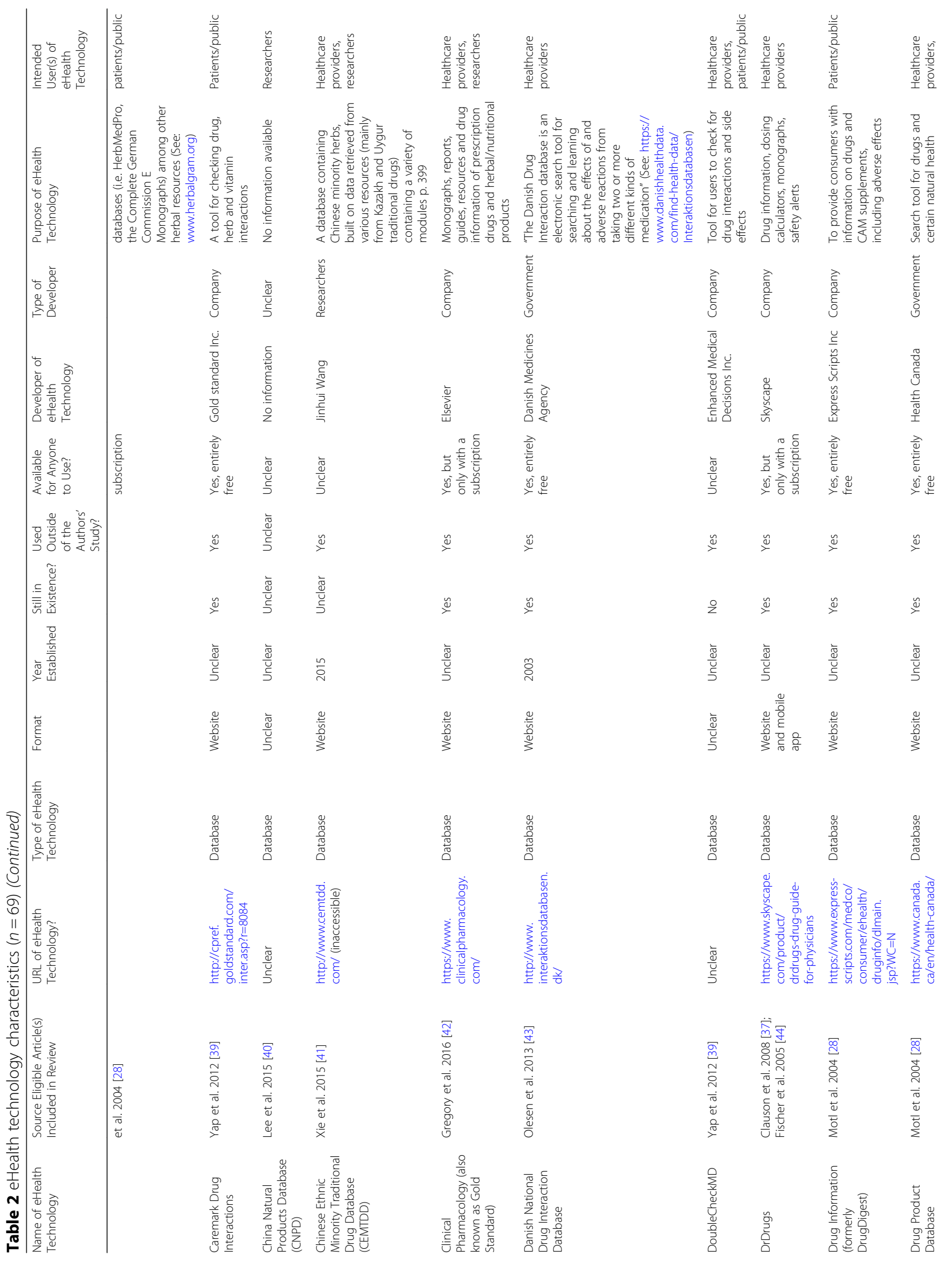




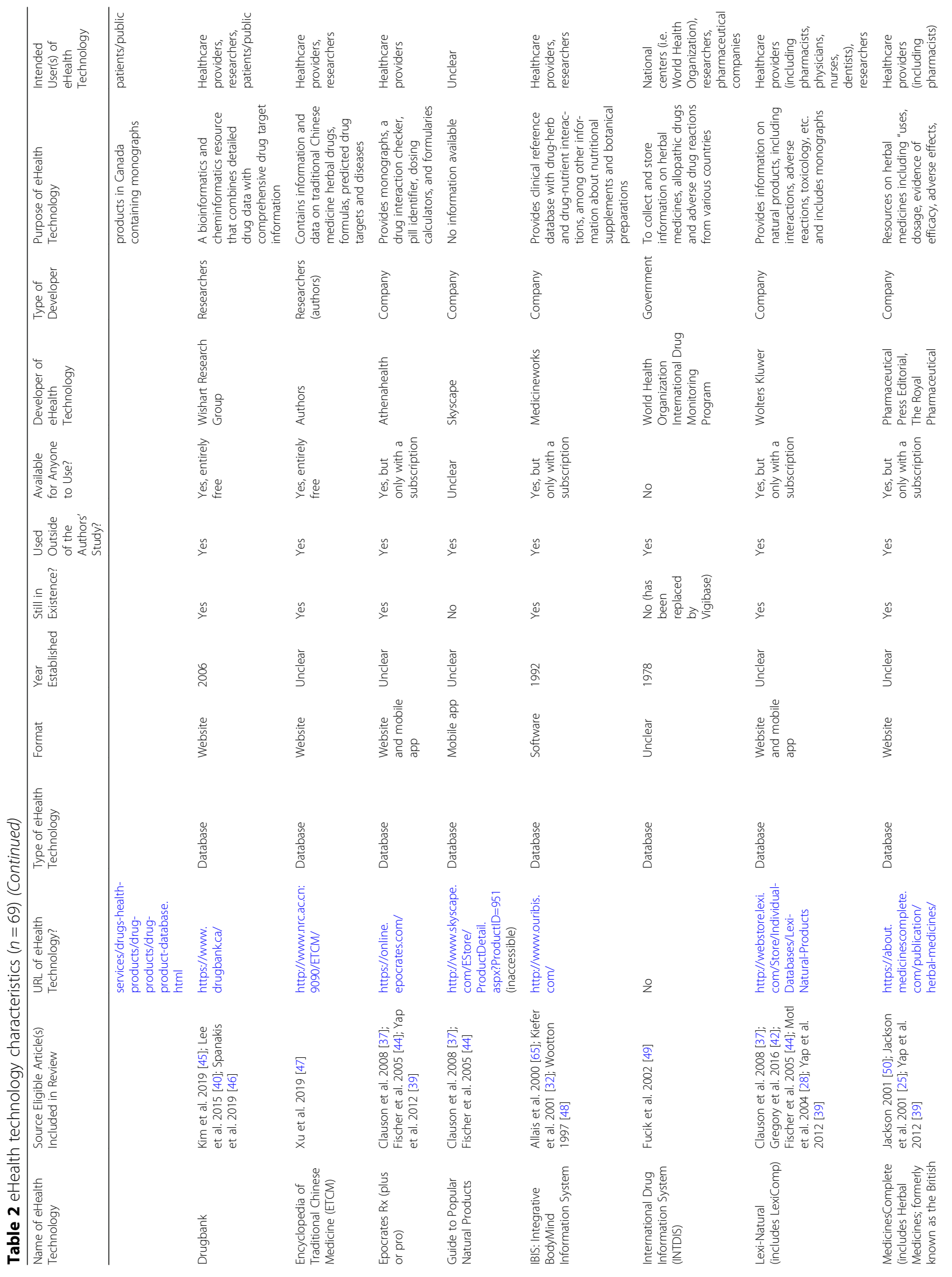




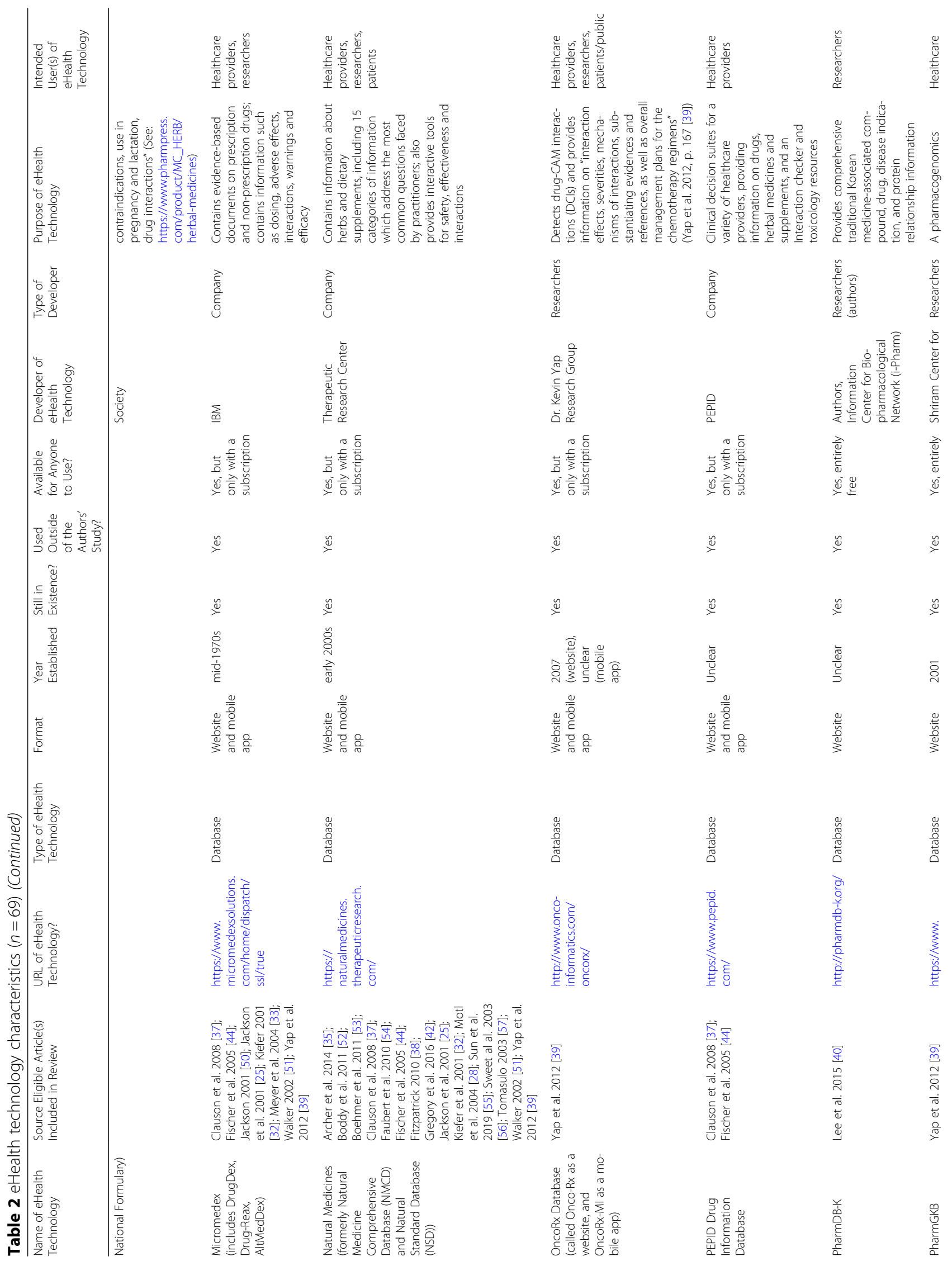




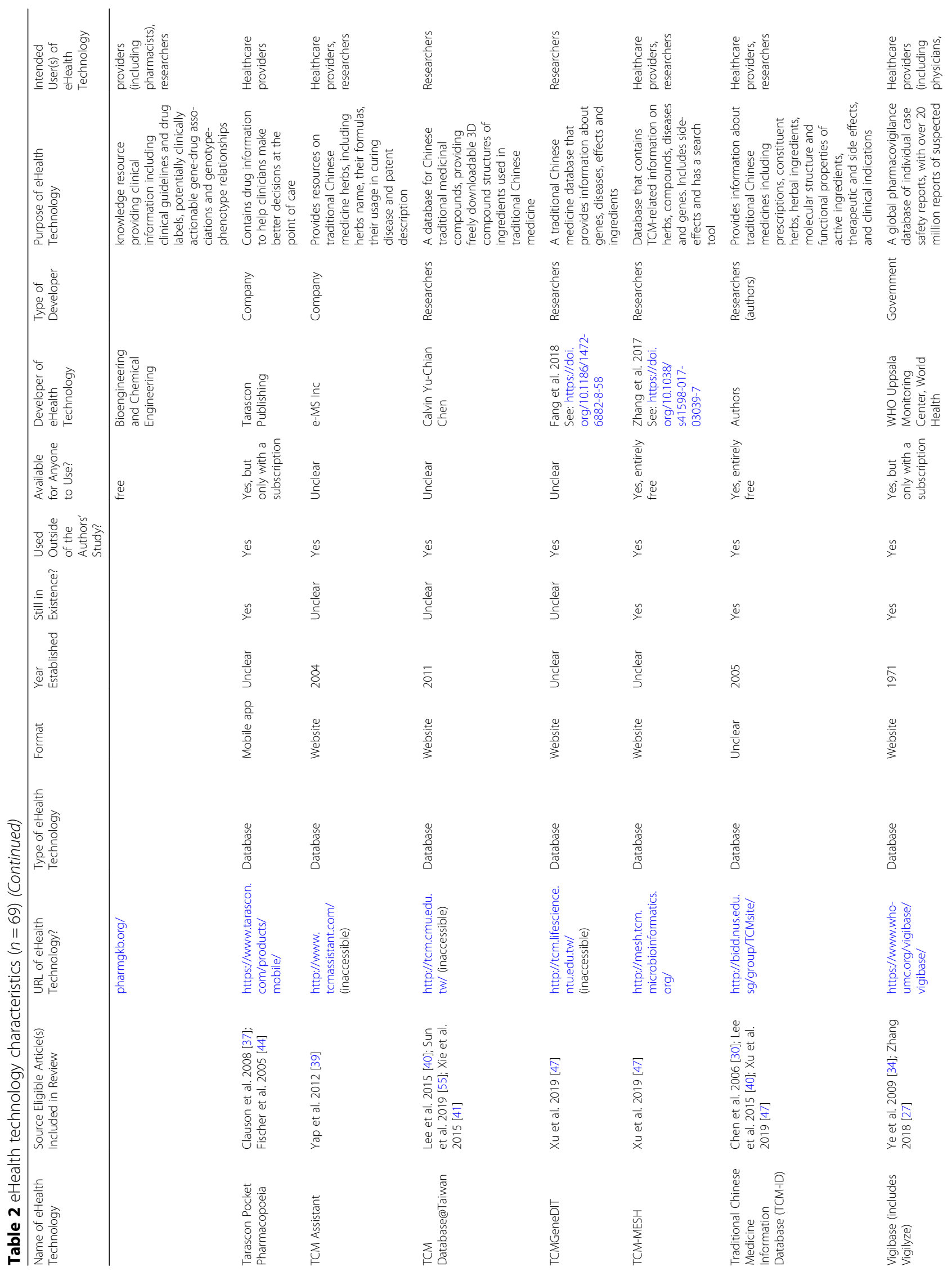




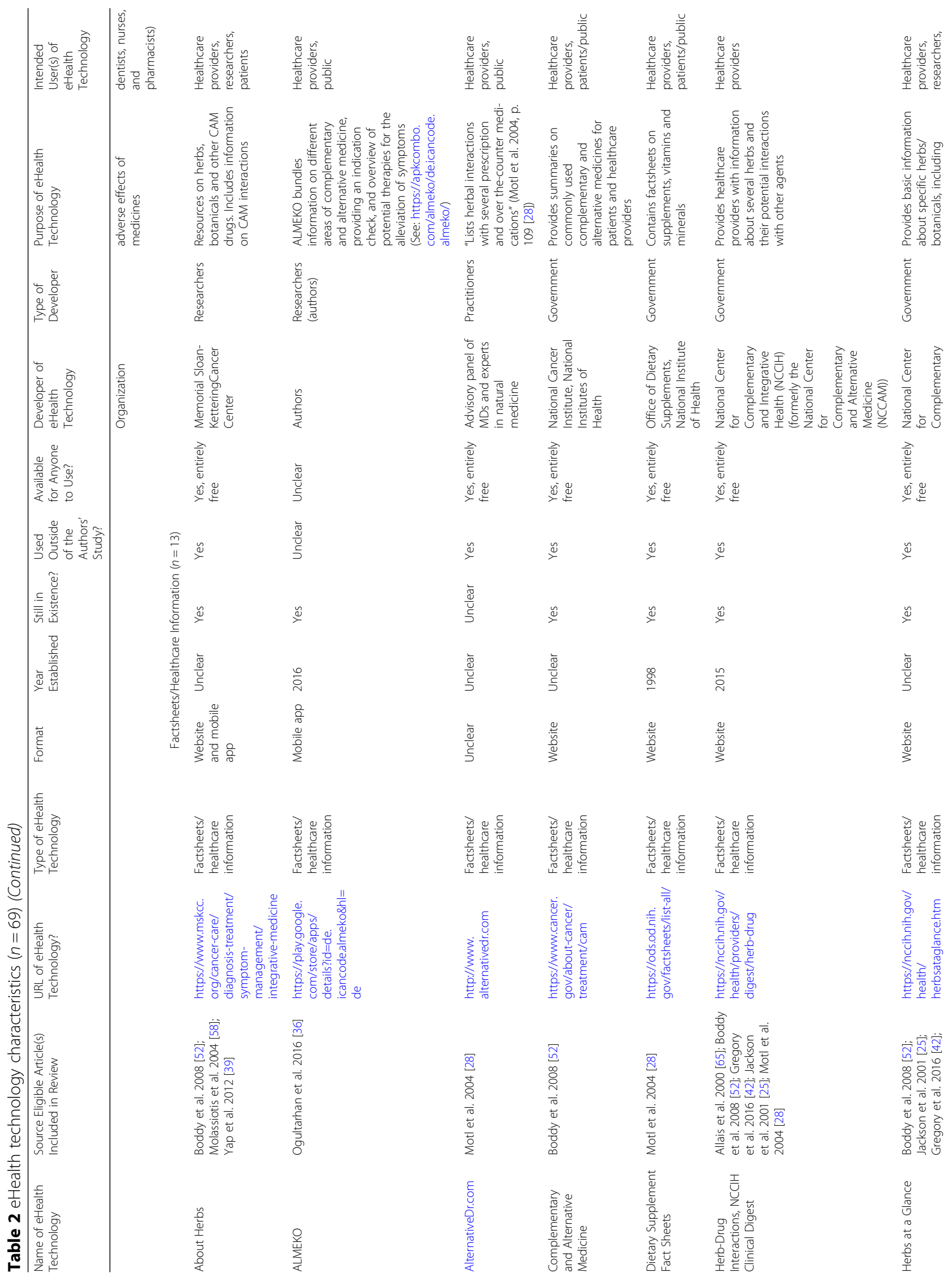




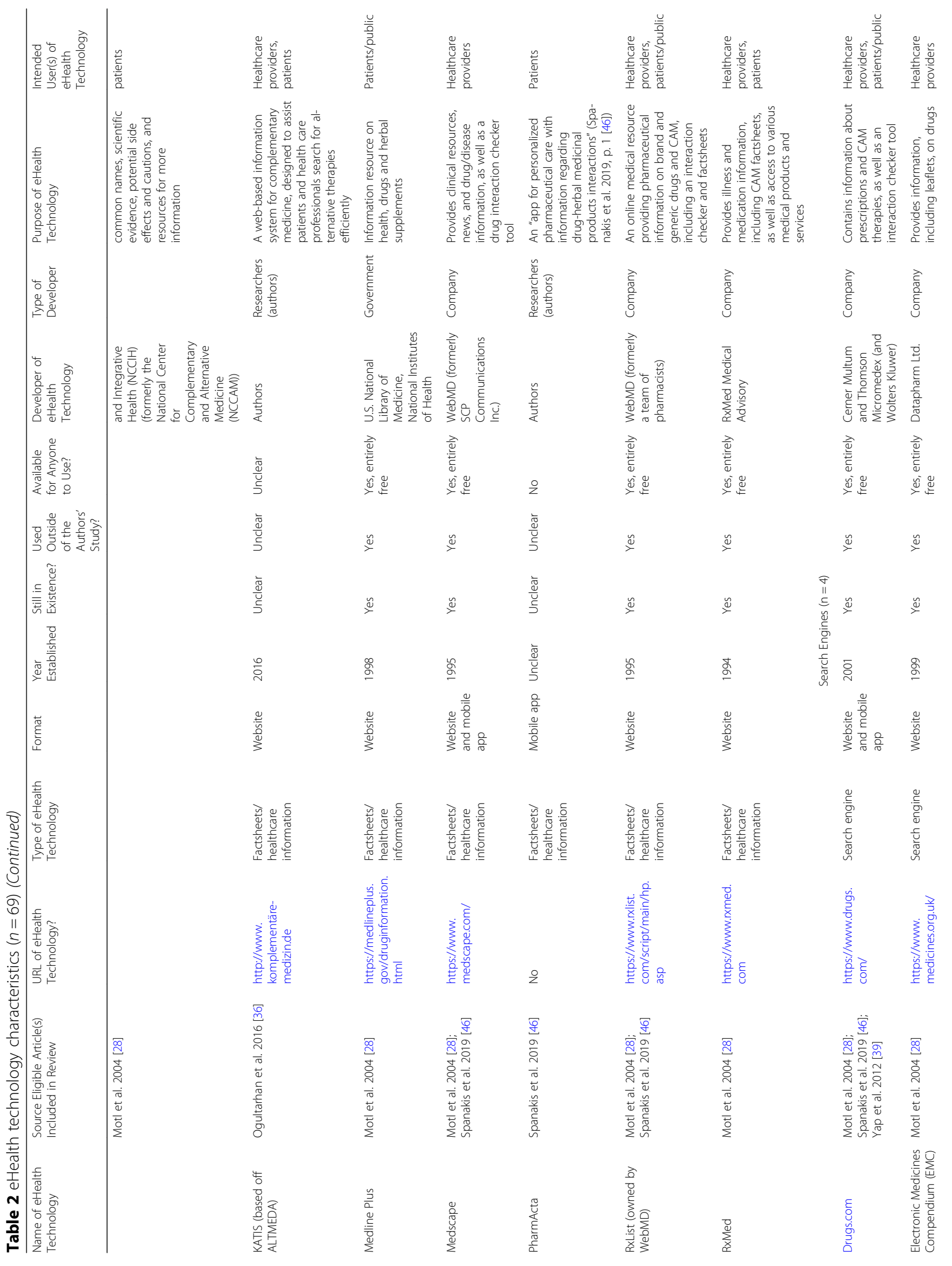




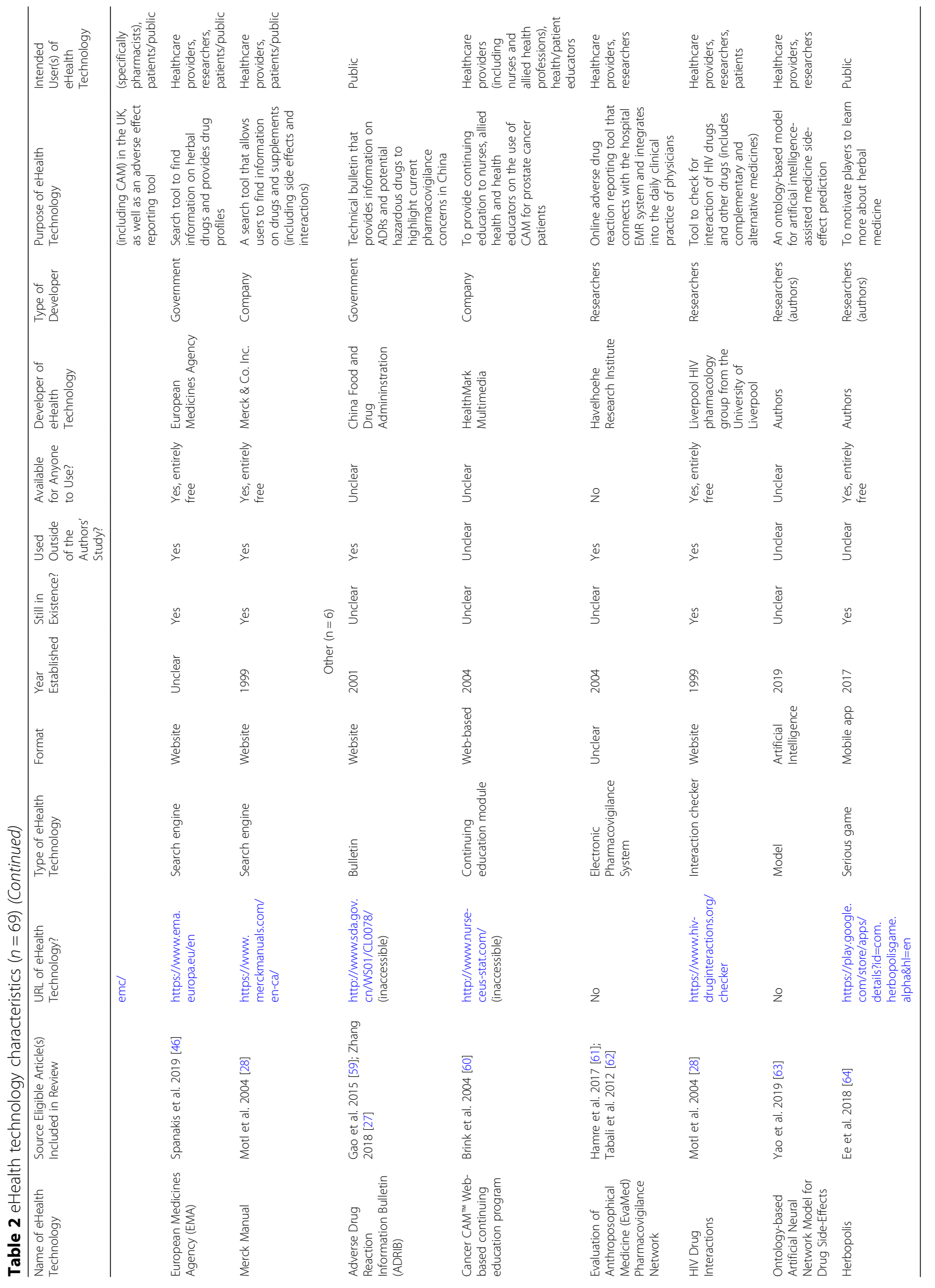


Table 3 Frequency of updates by database identified via eligible articles

\begin{tabular}{ll}
\hline Database name & URL \\
\hline ABDAMED & https://abdata.de/datenangebot/abdamed/ \\
Alticopeia Herbal Medicine Database & http://www.ddhsoftware.com/gallery.html?show= \\
& number\&record=527
\end{tabular}

ALTMEDA Unclear

American Botanical Council

http://abcherbalgram.org/site/PageServer

Caremark Drug Interactions

http://cpref.goldstandard.com/inter.asp?r=8084

China Natural Products Database (CNPD) Unclear

Chinese Ethnic Minority Traditional Drug Database (CEMTDD)

Clinical Pharmacology

Danish National Drug Interaction Database

DoubleCheckMD

DrDrugs

Drug Information- formerly named DrugDigest

Drug Product Database

\section{DrugBank}

Encyclopedia of Traditional Chinese Medicine (ETCM)

Epocrates Rx (plus or pro)

Guide to Popular Natural Products

IBIS: Integrative BodyMind Information System

International Drug Information System (INTDIS):

Lexi-Natural (includes LexiComp) http://www.cemtdd.com/

https://www.clinicalpharmacology.com/

http://www.interaktionsdatabasen.dk/

Unclear

https://www.skyscape.com/product/drdrugs-drugguide-for-physicians

https://www.express-scripts.com/medco/ consumer/ehealth/druginfo/dlmain.jsp?WC=N

https:/www.canada.ca/en/health-canada/services/ drugs-health-products/drug-products/drugproduct-database.html

https://www.drugbank.ca/

http://www.nrc.ac.cn:9090/ETCM/

https://online.epocrates.com/

http://www.skyscape.com/EStore/ProductDetail. aspx?Product|D=951 (inaccessible)

N/A

http://webstore.lexi.com/Store/IndividualDatabases/Lexi-Natural-Products http://www.ouribis.com/
Frequency of updates

The content is updated daily.

The website states that this database was last updated on January 11, 2009. The frequency of updates is not available.

This database cannot be located outside the author's original publication. The frequency of updates is not available.

Dates of updates to $A B C$ 's product-specific and botanical ingredient monographs range from 2009 to 2019. Information on the frequency of updates made to $A B C$ Clinical Guide to Herbs database is not available.

Interaction reports list dates of revisions that range from 2016 to 2019. The frequency of updates is not available.

While this database has been mentioned in other papers, the database cannot be located, and the frequency of updates is not available.

The database is still publicly available and maintained but no updates are apparent since the database was created 2014

The content is updated daily.

The website states that this database is updated "constantly". The precise frequency of updates is not explicitly listed.

While this database has been mentioned in other papers, the database cannot be located, and the frequency of updates is not available.

The exact frequency of updates will vary based on the publisher's availability, but drug databases are updated on a monthly or quarterly basis.

The website states that the site homepage was last updated on 04/20/2020. However, dates are not listed for the drug profiles in the database, therefore the frequency of updates is not available.

The website states that monographs are updated after a marketing drug has been authorized, but update frequency is not explicitly stated. Database appears to be updated up until 2020.

The content is updated daily.

In their paper, Xu et al. 2019 [47] advised that the database would continue to be updated. The database is maintained but the frequency of updates is not explicitly listed.

The content is updated daily.

This database no longer exists. The frequency of updates when the database was in existence is not available.

Update frequency is not mentioned clearly. The database was not working for a period of time, and became available again in 2010, The last update appears to be in 2013.

The INTDIS no longer exists, as it has been replaced by Vigibase.

The content of LexiComp is updated daily. It is stated that the online version has been updated 1-5 time(s) a year, but the last update is recorded as June 2018. 
Table 3 Frequency of updates by database identified via eligible articles (Continued)

\begin{tabular}{l} 
Database name \\
\hline MedicinesComplete (includes Herbal \\
Medicines; formerly known as the British \\
National Formulary) \\
Micromedex (includes DrugDex, Drug- \\
Reax, AltMedDex) \\
Natural Medicines (formerly Natural \\
Medicine Comprehensive Database \\
(NMCD) and Natural Standard Database \\
(NSD))
\end{tabular}

OncoRx Database (called Onco-Rx as a website, and OncoRx-Ml as a mobile app)

PEPID Drug Information Database

PharmDB-K

PharmGKB URL

https://about.medicinescomplete.com/publication/ herbal-medicines/

https://www.micromedexsolutions.com/home/ dispatch/ssl/true

https://naturalmedicines.therapeuticresearch.com/ Frequency of updates MedicinesComplete is updated 3-4 times a year, usually in January, April, July, and October.

The content is updated daily.

The content is updated daily.

\begin{abstract}
https://www.pepid.com/
\end{abstract}
http://biomart.i-pharm.org http://pharmdb-k.org/

http://www.onco-informatics.com/oncorx/

https://www.pharmgkb.org
Tarascon Pocket Pharmacopoeia

TCM Assistant

TCM Database@Taiwan

TCMGeneDIT

TCM-MESH

Traditional Chinese Medicine Information Database (TCM-ID)

Vigibase (includes Vigilyze) https://www.tarascon.com/products/mobile/

http://www.tcmassistant.com/

http://tcm.cmu.edu.tw/

http://tcm.lifescience.ntu.edu.tw/

http://mesh.tcm.microbioinformatics.org/

http://bidd.nus.edu.sg/group/TCMsite/ New URL: http://119.3.41.228:8000/tcmid/ 2017 Version: Huang L, Xie D, Yu Y, Liu H, Shi Y, Shi T, Wen C. TCMID 2.0: a comprehensive resource for TCM. Nucleic acids research. 2018 Jan 4;46(D1):D1117-20.

https://www.who-umc.org/vigibase/vigibase/
The update frequency is not clear, though likely at least annually. The last update was reported in 2019.

Update frequency is not mentioned clearly. It was mentioned that the content is updated "continuously" and "regularly".

There is no information available. Neither links provided lead to an accessible website.

Literature annotations and variant annotations are added in real time as a curator annotates the paper. Very important pharmacogene (VIP) summaries, curated pathways and clinical annotations are reviewed periodically. New clinical guideline annotations and drug label annotations are added as they become evident. Gene, drug and disease data that is automatically retrieved is updated in response to scheduled updates at the external resource.

The frequency of updates is not clear, but the last update was in 2020.

There is no information available regarding update frequency, and the website is inaccessible.

There is no information available regarding update frequency, and the website is inaccessible.

There is no information available regarding update frequency, and the website is inaccessible.

There is no information available regarding update frequency, and the website is inaccessible.

The first version of TCM-ID was released in 2012. Since this time, however, a second version was released in 2017 (see new URL with accompanying citation). The frequency of updates since 2017 is unclear.

VigiBase is continuously updated with reports, sometimes daily, as they are submitted by member countries of the World Health Organization Programme for International Drug Monitoring. Most national centres report quarterly or even more frequently. The date of occurrence is noted when supplied, and the date of entry into VigiBase is recorded. 
Table 4 Databases created and/or updated within the last 3 years identified via eligible articles

\begin{tabular}{lll}
\hline Databases & URL & Summary \\
\hline Publicly Available & http://abc.herbalgram.org/site/PageServer & The American Botanical Council provides a searchable \\
American Botanical Council & $\begin{array}{l}\text { database titled "ABC Clinical Guide to Herbs" that } \\
\text { includes monographs, clinical overviews, and patient } \\
\text { information sheets for various herbs. While access to this } \\
\text { database requires a paid subscription, the resource also } \\
\text { offers free databases with information on herbal and } \\
\text { plant-based ingredients, herb profiles and select herbal } \\
\text { monographs. }\end{array}$ &
\end{tabular}

Caremark Drug Interactions

Danish National Drug Interaction Database

Drug Information- formerly named DrugDigest

Drug Product Database

DrugBank

Encyclopedia of Traditional Chinese Medicine (ETCM)

PharmGKB

Traditional Chinese Medicine Information Database (TCM-ID)

\section{Requiring Paid Subscription}

Clinical Pharmacology

DrDrugs

Epocrates Rx (plus or pro)

Lexi-Natural (includes LexiComp)

MedicinesComplete (includes Herbal Medicines; formerly known as the British National Formulary)

Micromedex (includes DrugDex, Drug-Reax, AltMedDex) http://cpref.goldstandard.com/inter.asp?r= 8084

http://www.interaktionsdatabasen.dk/

https://www.express-scripts.com/medco/ consumer/ehealth/druginfo/dlmain.jsp?WC= $\mathrm{N}$

https://www.canada.ca/en/health-canada/ services/drugs-health-products/drugproducts/drug-product-database.html

https://www.drugbank.ca/

http://www.nrc.ac.cn:9090/ETCM/

https://www.pharmgkb.org

http://119.3.41.228:8000/tcmid/

https://www.clinicalpharmacology.com/

https://www.skyscape.com/product/ drdrugs-drug-guide-for-physicians

https://online.epocrates.com/

http://webstore.lexi.com/Store/IndividualDatabases/Lexi-Natural-Products

https://about.medicinescomplete.com/ publication/herbal-medicines/

https://www.micromedexsolutions.com/ home/dispatch/ssl/true
Copyrighted through Gold Standard, the Caremark Drug Interactions database includes a drug-interaction search tool. Reports are provided for interactions between drugs, CAM, food, alcohol, and other substances.

The Danish Medicines Agency provides a searchable interactive database for prescription drugs, herbal remedies, vitamins, minerals, and grapefruit juice.

The Drug Information database includes a search tool to find monographs and information on medications, herbal drugs, and supplements. While several drugs are indexed in the database, the majority of drugs do not have a monograph available.

The Drug Product Database is maintained by Health Canada through the Government of Canada and contains a searchable database for drugs authorized for sale in Canada. While several drugs are indexed in the database, many do not have product monographs available.

The Drugbank database provides information on drugs and drug/chemical target information.

ETCM is an online searchable database that provides data on the ingredients, herbs, and formulas of Traditional Chinese Medicine.

PharmGKB is a searchable pharmacogenomic database targeted for researchers that provides data on the relationship between genetic variations and drug response. Molecules, genes, or variants can be searched within the database.

In its second revision, the TCM-ID database provides information on the relationships between the herbs and formulas and the pharmacology or biochemistry of Traditional Chinese Medicine.

Clinical Pharmacology is a drug information resource that is powered by Clinical Key and owned by Gold Standard. The database contains monographs for prescription drugs as well as CAM products.

DrDrugs provides a mobile and web-based database of monographs for drugs and herbal products.

Epocrates offers a web-based and mobile version of their database of drug monographs and interaction reports.

Lexi-Natural is part of the Lexicomp database and includes drug monographs and patient handouts for both prescription drugs and CAM products.

Developed by the Royal Pharmaceutical Society, MedicinesComplete provides a database of drug and CAM monographs and drug interaction reports.

IBM Micromedex provides a searchable database of drug and CAM monographs as well as disease and toxicology 
Table 4 Databases created and/or updated within the last 3 years identified via eligible articles (Continued)

\begin{tabular}{|c|c|c|}
\hline Databases & URL & Summary \\
\hline $\begin{array}{l}\text { Natural Medicines (formerly Natural Medicine } \\
\text { Comprehensive Database (NMCD) and } \\
\text { Natural Standard Database (NSD)) }\end{array}$ & $\begin{array}{l}\text { https://naturalmedicines. } \\
\text { therapeuticresearch.com/ }\end{array}$ & $\begin{array}{l}\text { Natural Medicines is a database with several sub- } \\
\text { databases on databases on food, herbs and supple- } \\
\text { ments, herbal combinations, drug manufacturers, sports } \\
\text { medicine, health and wellness and a comparative effect- } \\
\text { iveness database. The database also features tools in- } \\
\text { cluding an interaction checker, effectiveness checker, } \\
\text { nutrient depletion, pregnancy and lactation checker and } \\
\text { adverse event checker. }\end{array}$ \\
\hline $\begin{array}{l}\text { OncoRx Database (called Onco-Rx as a web- } \\
\text { site, and OncoRx-Ml as a mobile app) }\end{array}$ & http://www.onco-informatics.com/oncorx/ & $\begin{array}{l}\text { Onco Rx is a database of interaction information for } \\
\text { oncology drugs, chemotherapy regimens and CAM } \\
\text { products. }\end{array}$ \\
\hline PEPID Drug Information Database & https://www.pepid.com/ & $\begin{array}{l}\text { PEPID Knowledgebase is a web-accessible database } \\
\text { hosted through PEPID Connect. Features of PEPID Con- } \\
\text { nect include: Drug interaction checker; drug-allergy } \\
\text { checker; pill identification; IV Compatibility tool; lab man- } \\
\text { uals; clinical calculators; drug database; differential diag- } \\
\text { nosis and symptom checker; news and alerts; PEPID PGx } \\
\text { pharmacogenomic tool. }\end{array}$ \\
\hline Tarascon Pocket Pharmacopoeia & $\begin{array}{l}\text { https://www.tarascon.com/products/ } \\
\text { mobile/ }\end{array}$ & $\begin{array}{l}\text { The Tarascon Pocket Pharmacopoeia database contains } \\
\text { drug guides and information on drug interactions. The } \\
\text { database comes in a PDA format and also includes } \\
\text { information on herbal supplements. }\end{array}$ \\
\hline
\end{tabular}

\begin{abstract}
Abbreviations
CADTH: Canadian Agency for Drugs and Technologies in Health; CAM: Complementary and alternative medicine; CAHTS: Computer-assisted history-taking systems; CDSS: Computerized decision support systems; mHealth: Mobile health; NCCIH: National Center for Complementary and Integrative Health; NHP: Natural health product
\end{abstract}

\section{Acknowledgements}

We gratefully acknowledge librarian Laura Banfield for providing guidance in constructing the search strategy. JYN was awarded a Research Scholarship and an Entrance Scholarship from the Department of Health Research Methods, Evidence and Impact, Faculty of Health Sciences at McMaster University.

\section{Authors' contributions}

JYN: conceptualized and designed the study, collected the data, interpreted and analysed the data, drafted the manuscript, and gave final approval of the version to be submitted. MM: collected the data, interpreted and analysed the data, provided contributions and critically revised the manuscript, and gave final approval of the version to be submitted. VM: collected the data, interpreted and analysed the data, provided contributions and critically revised the manuscript, and gave final approval of the version to be submitted. All authors have read and approved the manuscript.

\section{Funding}

This study was not funded.

\section{Availability of data and materials}

All data generated or analysed during this study are included in this published article [and its supplementary information files].

\section{Ethics approval and consent to participate}

This study involved a systematic search of the literature only; it did not require ethics approval or consent to participate.

\section{Consent for publication}

All authors consent to this manuscript's publication in the order in which the authors are listed in the cover sheet.

\section{Competing interests}

The authors declare that they have no competing interests.
Received: 10 January 2020 Accepted: 19 May 2020

Published online: 29 July 2020

\section{References}

1. Fugh-Berman A. Herb-drug interactions. Lancet. 2000;355(9198):134-8

2. Barnes PM, Powell-Griner E, McFann K, Nahin RL. Complementary and alternative medicine use among adults: United States, 2002. Semin Integr Med. 2004;2(2):54-71.

3. Eisenberg DM, Davis RB, Ettner SL, Appel S, Wilkey S, Van Rompav M, et al. Trends in alternative medicine use in the United States, 1990-1997: results of a follow-up national survey. JAMA. 1998;280(18):1569-75.

4. Public Health Agency of Canada. Canada.ca: Government of Canada; 2019 [updated 2019 Dec 10; cited 2019 Dec 14]. Available from: http://www. phac-aspc.gc.ca/chn-rcs/cah-acps-eng.php.

5. Esmail N. Complementary and alternative medicine in Canada: trends in use and public attitudes, 1997-2006. Public Policy Sources. 2007:87:1-53.

6. Nahin RL, Barnes PM, Stussman BJ, Bloom B. Costs of complementary and alternative medicine (CAM) and frequency of visits to CAM practitioners: United States, 2007. Natl Health Stat Rep. 2009;(18):1-14.

7. Health Canada. Summary report on the consultation on a framework for consumer health products: what we heard [Internet]. Canada.ca: Government of Canada; 2016 [updated 2016 Apr 01; cited 2019 Dec 14]. Available from http://www.hc-sc.gc.ca/dhp-mps/consultation/natur/sum_ chpf-som_cpsc-eng.php.

8. Ipsos Reid. Natural health product tracking survey - 2010 final report. Ottawa: Health Canada; 2011. 72 p. Available from http://epe.lac-bac.gc.ca/1 00/200/301/pwgsc-tpsgc/por-ef/health/2011/135-09/report.pdf.

9. Andersson ML, Böttiger Y, Lindh JD, Wettermark B, Eiermann B. Impact of the drug-drug interaction database SFINX on prevalence of potentially serious drug-drug interactions in primary health care. Eur I Clin Pharmacol. 2013;69(3):565-71.

10. Hammar T, Lidström B, Petersson G, Gustafson Y, Eiermann B. Potential drug-related problems detected by electronic expert support system: physicians' views on clinical relevance. Int J Clin Pharm. 2015;37(5):941-8.

11. Apidi NA, Murugiah MK, Muthuveloo R, Soh YC, Caruso V, Patel R, et al. Mobile medical applications for dosage recommendation, drug adverse reaction, and drug interaction: review and comparison. Ther Innov Regul Sci. 2017:51(4):480-5.

12. Kim BY, Sharafoddini A, Tran N, Wen EY, Lee J. Consumer mobile apps for potential drug-drug interaction check: systematic review and content analysis using the mobile app rating scale (MARS). JMIR Mhealth and Uhealth. 2018;6(3):e74. 
13. Larsen M, Rowntree J, Young A, Pearson S, Smith J, Gibson O, et al. Chemotherapy side-effect management using mobile phones. Conf Proc IEEE Eng Med Biol Soc. 2008;2008:5152-5.

14. Car J, Tan WS, Huang Z, Sloot P, Franklin BD. eHealth in the future of medications management: personalisation, monitoring and adherence. eHealth in the future of medications management: personalisation, monitoring and adherence. BMC Med. 2017;15(1):73.

15. Arksey H, O'Malley L. Scoping studies: towards a methodological framework. Int J Soc Res Methodol. 2005;8(1):19-32.

16. Levac D, Colquhoun H, O'Brien KK. Scoping studies: advancing the methodology. Implement Sci. 2010;5(1):69.

17. Daudt HM, van Mossel C, Scott SJ. Enhancing the scoping study methodology: a large, inter-professional team's experience with Arksey and O'Malley's framework. BMC Med Res Methodol. 2016;13(1):48.

18. Oh H, Rizo C, Enkin M, Jadad A. What is eHealth (3): a systematic review of published definitions. J Med Internet Res. 2005;7(1):e1.

19. Shaw T, Mcgregor D, Brunner M, Keep M, Janssen A, Barnet S. What is eHealth (6)? Development of a conceptual model for eHealth: qualitative study with key informants. J Med Internet Res. 2017;19(10):e324.

20. Ng JY, Boon HS, Thompson AK, Whitehead CR. Making sense of "alternative", "complementary", "unconventional" and "integrative" medicine: exploring the terms and meanings through a textual analysis. BMC Complement Altern Med. 2016;16(1):134.

21. National Center for Complementary and Integrative Health $(\mathrm{NCClH})$. Complementary, alternative, or integrative health: what's in a name? [Internet] U.S. Department of Health and Human Services; 2018 [updated 2018 Jul; cited 2019 Dec 14]. Available from: https://nccih.nih.gov/health/integrative-health.

22. Wieland LS, Manheimer E, Sampson M, Barnabas JP, Bouter LM, Cho K, et al. Bibliometric and content analysis of the Cochrane complementary medicine field specialized register of controlled trials. Syst Rev. 2013;2(1):51.

23. World Health Organization (WHO). Safety monitoring of medicinal products: guidelines for setting up and running a pharmacovigilance centre [Internet] Geneva: World Health Organization and the Uppsala Monitoring Centre; 2000. [cited 2019 Dec 14]. Available from: https://www.who-umc.org/ media/1703/24747.pdf.

24. Mitchell JG. From telehealth to e-health: the unstoppable rise of e-health. Canberra, A.C.T.: Commonwealth Department of Communications, Information Technology and the Arts; 1999.

25. Jackson EA, Kanmaz T. An overview of information resources for herbal medicinals and dietary supplements. J Herb Pharmacother. 2001;1(1):35-61.

26. Li C, Xia J, Deng J, Chen W, Wang S, Jiang J, et al. A web-based quantitative signal detection system on adverse drug reaction in China. Eur J Clin Pharmacol. 2009:65(7):729-41.

27. Zhang L. Pharmacovigilance of herbal and traditional medicines. Methods in pharmacology and toxicology evidence-based pharmacovigilance. New York: Humana Press; 2018. p. 37-65

28. Motl SE, Timpe EM, Robinson M, Corsberg C, Phillips K. Health information web sites by therapeutic category for healthcare professionals. J Pharm Technol. 2004;20(2):106-18.

29. Chen YZ, Ung CY. Computer automated prediction of potential therapeutic and toxicity protein targets of bioactive compounds from Chinese medicinal plants. Am J Chin Med. 2002;30(1):139-54.

30. Chen $X$, Zhou H, Liu YB, Wang JF, Li H, Ung CY, et al. Database of traditional Chinese medicine and its application to studies of mechanism and to prescription validation. Br J Pharmacol. 2006;149(8):1092-103.

31. Woo Y, Hyun MK. Safety of herbal medicine for elderly patients with chronic disease in the Republic of Korea. Eur J Integr Med. 2019;30:100934.

32. Kiefer D, Shah S, Gardiner P, Wechkin H. Finding information on herbal therapy: a guide to useful sources for clinicians. Altern Ther Health Med. 2001;7(6):74-8

33. Meyer JR, Generali JA, Karpinski JL. Evaluation of herbal-drug interaction data in tertiary resources. Hosp Pharm. 2004;39(2):149-60.

34. Ye X, Fu Z, Wang H, Du W, Wang R, Sun Y, et al. A computerized system for signal detection in spontaneous reporting system of Shanghai China. Pharmacoepidemiol Drug Saf. 2009;18(2):154-8.

35. Archer M, Proulx J, Shane-McWhorter L, Bray BE, Zeng-Treitler Q. Development of an alert system to detect drug interactions with herbal supplements using medical record data. AMIA Annu Symp Proc. 2014:2014:249-55.

36. Ogultarhan V, Shoshi A, Magnucki R, Kormeier B, Hofestädt R. KATIS: an eHealth system for complementary medicine. IOS Press Ebooks. 2016;223: 167-73.
37. Clauson KA, Polen HH, Peak AS, Marsh WA, DiScala SL. Clinical decision support tools: personal digital assistant versus online dietary supplement databases. Ann Pharmacother. 2008;42(11):1592-9.

38. Fitzpatrick RB. Natural Standard Database. Med Ref Serv Q. 2010;29(2): 154-65.

39. Yap KY, See CS, Kuo EY, Chui WK, Chan A. Utilizing mobile networks for the detection of clinically relevant interactions between chemotherapy regimens and complementary and alternative medicines. J Altern Complement Med. 2012;18(2):165-74.

40. Lee JH, Park KM, Han DJ, Bang NY, Kim DH, Na H, et al. PharmDB-K: integrated bio-pharmacological network database for traditional Korean medicine. PLoS One. 2015;10(11):e0142624.

41. Xie T, Song S, Li S, Ouyang L, Xia L, Huang J. Review of natural product databases. Cell Prolif. 2015;48(4):398-404.

42. Gregory PJ, Jalloh MA, Abe AM, Hu J, Hein DJ. Characterization of complementary and alternative medicine-related consultations in an academic drug information service. J Pharm Pract. 2016;29(6):539-42.

43. Olesen C, Harbig P, Barat I, Damsgaard EM. Absence of 'over-the-counter' medicinal products in on-line prescription records: a risk factor of overlooking interactions in the elderly. Pharmacoepidemiol Drug Saf. 2013; 22(2):145-50.

44. Fischer JE, Crowell K, Curtis P. Complementary and alternative medical reference software for personal digital assistants: evidence of clinical applicability. Complement Health Pract Rev. 2005;10(1):57-72.

45. Kim E, Choi AS, Nam H. Drug repositioning of herbal compounds via a machine-learning approach. BMC Bioinformatics. 2019;20(S10):247.

46. Spanakis M, Sfakianakis S, Sakkalis V, Spanakis E. PharmActa: empowering patients to avoid clinical significant drug-herb interactions. Medicines. 2019; $6(1): 26$.

47. Xu HY, Zhang YQ, Liu ZM, Chen T, Lv CY, Tang SH, et al. ETCM: an encyclopaedia of traditional Chinese medicine. Nucleic Acids Res. 2019; 47(D1):D976-82.

48. Wootton JC. Directory of databases for research into alternative and complementary medicine. J Altern Complement Med. 1997;3(2):179-90.

49. Fucik H, Backlund A, Farah M. Building a computerized herbal substance register for implementation and use in the World Health Organisation international drug monitoring Programme. Drug Inform J. 2002;36(4):839-54.

50. Jackson EA. Resources for information on herbal medicinals and dietary supplements. J Herb Pharmacother. 2001;1(2):89-98.

51. Walker JB. Evaluation of the ability of seven herbal resources to answer questions about herbal products asked in drug information centers. Pharmacotherapy. 2002;22(12):1611-5.

52. Boddy K, Ernst E. Review of reliable information sources related to integrative oncology. Hematol Oncol Clin North Am. 2008;22(4):619-30.

53. Boehmer S, Karpa K. Evaluating the value of a web-based natural medicine clinical decision tool at an academic medical center. BMC Health Serv Res. 2011;11(1):279.

54. Faubert G, Lebe D, Bussières JF. A pilot study to compare natural health product-drug interactions in two databases in Canada. Pharm World Sci. 2010;32(2):179-86

55. Sun Y, Shi S, Li Y, Wang Q. Development of quantitative structure-activity relationship models to predict potential nephrotoxic ingredients in traditional Chinese medicines. Food Chem Toxicol. 2019;128:163-70.

56. Sweet BV, Gay WE, Leady MA, Stumpf JL. Usefulness of herbal and dietary supplement references. Ann Pharmacother. 2003:37(4):494-9.

57. Tomasulo P. Natural standard-new integrative medicine database. Med Ref Serv Q. 2003;22(3):33-8.

58. Molassiotis A, Xu M. Quality and safety issues of web-based information about herbal medicines in the treatment of cancer. Complement Ther Med. 2004;12(4):217-27.

59. Gao P, Zhang CL, Zeng FD, Pu R, Zhang J, Huang R, et al. Pharmacovigilance in China: issues of concern identified through an analysis of the Chinese adverse drug reaction information bulletin 2001 to 2014. J Clin Pharm Ther. 2015:40(5):594-8.

60. Brink SG, Mcfarren AE, Lincoln JM, Birney AJ. Cancer $C A M^{\mathrm{T} M}$ : web-based continuing education for health professionals. Complement Health Pract Rev. 2004;9(1):43-60.

61. Hamre HJ, Glockmann A, Heckenbach K, Matthes H. Use and safety of anthroposophic medicinal products: an analysis of 44,662 patients from the EvaMed Pharmacovigilance network. Drugs Real World Outcomes. 2017;4(4): 199-213. 
62. Tabali M, Ostermann T, Jeschke E, Witt CM, Matthes H. Adverse drug reactions for CAM and conventional drugs detected in a network of physicians certified to prescribe CAM drugs. J Manag Care Pharm. 2012; 18(6):427-38.

63. Yao Y, Wang Z, Li L, Lu K, Liu R, Liu Z, et al. An ontology-based artificial intelligence model for medicine side-effect prediction: taking traditional Chinese medicine as an example. Comput Math Methods Med. 2019;2019: $1-7$.

64. Ee RW, Yap KZ, Yap KY. Herbopolis - a mobile serious game to educate players on herbal medicines. Complement Ther Med. 2018;39:68-79.

65. Allais G, Voghera D, Lorenzo CD, Mana O, Benedetto C. Access to databases in complementary medicine. J Altern Complement Med. 2000;6(3):265-74.

66. Clinical Pharmacology. Clinical pharmacology [Internet]. Elsevier Gold Standard [cited 2019 Dec 14]. Available from: https://www. clinicalpharmacology.com/.

67. IBM Watson Health Products. Micromedex web applications access [Internet]. Armonk: IBM Corporation; 2019. [cited 2019 Dec 14]. Available from: https://www.micromedexsolutions.com/home/dispatch/ssl/true.

68. Lexicomp. Lexi-natural products. Alphen aan den Rijn: Wolters Kluwer Clinical Drug Information, Inc; 2019. [cited 2019 Dec 14]. Available from: http://webstore.lexi.com/Store/Individual-Databases/Lexi-Natural-Products.

69. Therapeutic Research Center. Natural medicines. Stockton: Therapeutic Research Center; 2019. [cited 2019 Dec 14]. Available from: https:// naturalmedicines.therapeuticresearch.com/.

70. MedicinesComplete. Herbal medicines. London: The Royal Pharmaceutical Society; 2019. [cited 2019 Dec 14]. Available from: https://about. medicinescomplete.com/publication/herbal-medicines.

71. PEPID. Clinical decision support. Phoenix: PEPID; 2019. [cited 2019 Dec 14]. Available from: https://www.pepid.com/.

72. Interaktionsdatabasen Danish Medicines Agency. Interaktionsdatabasen.dk [Internet]. [cited 2019 Dec 14]. Available from: http://www. interaktionsdatabasen.dk/.

73. Uppsala Monitoring Centre. Vigibase. Swedan: WHO Collaborating Centre for International Drug Monitoring; 2019. [cited 2019 Dec 14]. Available from: https://www.who-umc.org/vigibase/vigibase/.

74. U.S. Food and Drug Administration (FDA). Center for Food Safety and Applied Nutrition (CFSAN) [Internet]. Silver Spring: FDA; 2018. [updated 2018 Sept 19; cited 2019 Dec 14]. Available from: https://www.fda.gov/about-fda/ office-foods-and-veterinary-medicine/center-food-safety-and-appliednutrition-cfsan.

75. U.S. Food and Drug Administration (FDA). Medical product safety information [Internet]. Silver Spring: FDA; 2019. [updated 2019 Dec 12; cited 2019 Dec 14]. Available from: https://www.fda.gov/safety/medwatch-fdasafety-information-and-adverse-event-reporting-program/medical-productsafety-information.

76. World Health Organization (WHO). WHO global report on traditional and complementary medicine 2019. Geneva: World Health Organization; 2019. [cited 2019 Dec 14]. Retrieved from https://www.who.int/traditionalcomplementary-integrative-medicine/ WhoGlobalReportOnTraditionalAndComplementaryMedicine2019.pdf?ua=1.

77. Institute For Safe Medication Practices. About us [Internet]. Horsham: Institute for Safe Medication Practices; 2019. [cited 2019 Dec 14]. Available from: https://www.ismp.org/about.

78. Ekor $M$. The growing use of herbal medicines: issues relating to adverse reactions and challenges in monitoring safety. Front Pharmacol. 2014:4:177.

79. National Center for Complementary and Integrative Health. Herbs at a glance [Internet]. Bethesda: U.S. Department of Health and Human Services; 2019. [updated 2019 Jun 20; cited 2019Dec14]. Available from: https://nccih. nih.gov/health/herbsataglance.htm.

80. Scarton LA, Del Fiol G, Treitler-Zeng Q. Completeness, accuracy, and presentation of information on interactions between prescription drugs and alternative medicines: an internet review. Stud Health Technol Inform. 2013; 192:841-5.

81. Kronenberg F, Molholt P, Zeng ML, Eskinazi D. A comprehensive information resource on traditional, complementary, and alternative medicine: toward an international collaboration. J Altern Complement Med. 2001;7(6):723-9.

82. Richardson J. Building CAM databases: the challenges ahead. J Altern Complement Med. 2002;8(1):7-8.

83. The EQUATOR Network. Your one-stop-shop for writing and publishing high-impact health research [Internet]. Headington: UK EQUATOR
Centre; 2019. [cited 2019 Dec 14]. Available from: https://www.equatornetwork.org/.

84. Baker TB, Gustafson DH, Shaw B, Hawkins R, Pingree S, Roberts L, et al. Relevance of CONSORT reporting criteria for research on eHealth interventions. Patient Educ Couns. 2010;81:S77-86.

85. Chen $Y Z$, Zhi DG. Ligand-protein inverse docking and its potential use in the computer search of protein targets of a small molecule. Proteins Struct Funct Genet. 2001;43:217-26.

\section{Publisher's Note}

Springer Nature remains neutral with regard to jurisdictional claims in published maps and institutional affiliations.
Ready to submit your research? Choose BMC and benefit from:

- fast, convenient online submission

- thorough peer review by experienced researchers in your field

- rapid publication on acceptance

- support for research data, including large and complex data types

- gold Open Access which fosters wider collaboration and increased citations

- maximum visibility for your research: over $100 \mathrm{M}$ website views per year

At BMC, research is always in progress.

Learn more biomedcentral.com/submissions 